\title{
Progress in space weather modeling in an operational environment
}

\author{
Ioanna Tsagouri ${ }^{1}{ }^{1 *}$, Anna Belehaki ${ }^{1}$, Nicolas Bergeot ${ }^{2,3},{\text { Consuelo } \mathrm{Cid}^{4} \text {, Véronique Delouille }}^{2,3}$, Tatiana Egorova ${ }^{5}$, \\ Norbert Jakowski $^{6}$, Ivan Kutiev ${ }^{7}$, Andrei Mikhailov ${ }^{8}$, Marlon Núñez ${ }^{9}$, Marco Pietrella ${ }^{10}$, Alexander Potapov ${ }^{11}$, \\ Rami Qahwaji ${ }^{12}$, Yurdanur Tulunay ${ }^{13}$, Peter Velinov ${ }^{7}$, and Ari Viljanen ${ }^{14}$ \\ 1 National Observatory of Athens, P. Penteli, Greece \\ *Corresponding author: e-mail: tsagouri@noa.gr \\ 2 Solar-Terrestrial Centre of Excellence, Brussels, Belgium \\ 3 Royal Observatory of Belgium, Brussels, Belgium \\ 4 Universidad de Alcalá, Alcalá de Henares, Spain \\ 5 Physikalisch-Meteorologisches Observatorium Davos and World Radiation Center (PMOD/WRC), Davos, Switzerland \\ 6 German Aerospace Center, Institute of Communications and Navigation, Neustrelitz, Germany \\ 7 Bulgarian Academy of Sciences, Sofia, Bulgaria \\ 8 Pushkov Institute of Terrestrial Magnetism, Ionosphere and Radio Wave Propagation (IZMIRAN), Troitsk, Moscow Region, \\ Russia \\ 9 Universidad de Málaga, Málaga, Spain \\ 10 Istituto Nazionale di Geofisica e Vulcanologia, Rome, Italy \\ 11 Institute of Solar-Terrestrial Physics SB RAS, Irkutsk, Russia \\ 12 University of Bradford, Bradford, UK \\ 13 Middle East Technical University, Ankara, Turkey \\ 14 Finnish Meteorological Institute, Helsinki, Finland
}

Received 19 June 2012 / Accepted 10 March 2013

\section{ABSTRACT}

\begin{abstract}
This paper aims at providing an overview of latest advances in space weather modeling in an operational environment in Europe, including both the introduction of new models and improvements to existing codes and algorithms that address the broad range of space weather's prediction requirements from the Sun to the Earth. For each case, we consider the model's input data, the output parameters, products or services, its operational status, and whether it is supported by validation results, in order to build a solid basis for future developments. This work is the output of the Sub Group 1.3 "Improvement of operational models" of the European Cooperation in Science and Technology (COST) Action ES0803 "Developing Space Weather Products and services in Europe" and therefore this review focuses on the progress achieved by European research teams involved in the action.
\end{abstract}

Key words. space weather - modelling - forecasting - services - space environment

\section{Introduction}

Space weather can be considered from two different stand points, the numerical modeling of the whole system on one hand, and the needs of the users, i.e., monitoring and forecasting the values of specific quantities, on the other hand (Lathuillere et al. 2002). One may argue that the two views are met collaboratively for the development of operational products and tools for space weather prediction purposes, which is a strong requirement for the reliable performance of several applications affected by space weather under all possible conditions. In this frame, much of the research efforts in the last decades are systematically spent for the development of advanced space weather models and techniques that are suitable for operational implementation to enhance our predictive capabilities within operational environments and meet the users' needs.

In general, an operational model should fulfill special requirements with respect to a purely "research" or "academic" model. An operational model should first and foremost fit users' requirements that may be expressed in several terms and specifications (e.g., parameters, prediction horizon and accuracy, accessibility). Among others, it also has to be validated and fully documented (Araujo-Pradere 2009). In addition, most of the users' requirements rely on the real-time implementation of the model, which is also considered to be a big challenge. Such a plan may require real-time data, as input to the model and sufficient computer skills to generate and provide also model's output in real or near-real-time mode. Consequently, there are many difficulties ranging from the data availability to information technology issues to be addressed. Overall, such developments usually face big scientific and technological challenges that require interdisciplinary knowledge, expertise, and collaboration. Most importantly, the challenges require the dynamic, bidirectional, and iterative interaction between scientists, service developers and providers, and users of space weather products and services in a systematic approach, since both the needs and the capabilities change dynamically with time.

In the United States (US), the National Space Weather Program (NSWP) has guided the US space weather efforts among agencies, research universities, and industry since the middle of 1990s (http://www.nswp.gov/). As a result, notable successes have been achieved in the development of operational space environment systems, supported by the successful transition 
of innovative research models into operations (Tobiska 2009). Space weather services in the US are provided primarily by the Space Weather Prediction Center (SWPC) of National Oceanic and Atmospheric Administration (NOAA) and the US Air Force's Weather Agency (AFWA), which collaborate to address the needs of their civilian and military user communities, respectively. Advanced operational activities for specialized applications are performed by the NASA Space Radiation Analysis Group at the Johnson Space Center, which work on the safety of astronauts against radiation exposure, and by the NASA Goddard Space Weather Research Center that aims at addressing the space weather needs of NASA's robotic missions. Finally, significant contribution in the US operational space weather services is provided by a number of commercial entities (see for instance http://www.swpc.noaa.gov/Vendors/ commercial.html).

The SWPC of NOAA (http://www.swpc.noaa.gov/), the US official source of space weather alerts and warnings, provides space weather services for civilian users under national and international collaborations. Among other activities, the SWPC explores and evaluates new models and products and transitions them into operations in close collaboration with users. Space weather models that have already been transitioned to operations by SWPC provide:

- Global Positioning System (GPS) Predictions: The USTotal Electron Content (US-TEC) product (Fuller-Rowell et al. 2006) is designed to specify vertical and slant TEC over the continental US.

- Communications Predictions:

(i) The Empirical STORM-time Ionospheric Correction Model (Araujo-Pradere et al. 2002) provides an estimate of the deviation from normal of the F-region critical frequency every hour of the day for the current and previous day.

(ii) The Global D-Region Absorption Product addresses the operational impact of the solar X-ray flux and SEP events on HF radio communication, providing a global map of the highest frequency affected by absorption of $1 \mathrm{~dB}$ due to either solar X-ray flux or SEP events or a combination of both, an attenuation bar graph, status messages, and an estimated recovery clock.

- Geomagnetic Predictions: The Wing Kp Predicted Geomagnetic Activity Index model (Wing et al. 2005) provides $1 \mathrm{~h}$ and $4 \mathrm{~h}$ predictions of the $K p$ index.

- Satellite Environments Predictions: The Relativistic Electron Forecast Model (REFM) predicts the $>2 \mathrm{MeV} 24-\mathrm{h}$ electron fluence at geo-synchronous orbit.

- Solar Wind Predictions:

(iii) The Wang-Sheeley-Arge (WSA) Model (Arge et al. 2004) predicts the background solar wind speed and the interplanetary magnetic field (IMF) polarity at Earth, two important parameters required for predicting geomagnetic activity.

(iv) The WSA-Enlil model (Pizzo et al. 2011) provides solar wind predictions in two modes, the ambient and the storm (CME-based) mode.

In Europe, a pioneering initiative to establish space weather research and its application as a pan-European endeavor was undertaken in the late 1990s by the European Space Agency (ESA) through the launch and further support of two feasibility studies carried out by two broad-based European consortia. They comprised members from academia, research establish- ments, and industry from different European countries. The results of the studies were published in 2001 and are available for download at http://www.esa-spaceweather.net/index.html (Watermann et al. 2009a). The study conducted by the consortium led by ALCATEL Space \& LPCE (France) yielded an overview of the scientific models available for space weather developments that was given by Lathuillere et al. (2002). Both empirical and physical models were systematically considered in this review to conclude highlighting the necessity of more developments and improvements of empirical models as a key driver of the development of operational space weather models and consequently, the necessity of routine availability of relevant direct measurements or scientifically agreed proxies.

ESA's studies were followed a couple of years later by the ESA sponsored Space Weather Applications Pilot Project (http://www.esa-spaceweather.net/spweather/esa_initiatives/pilotproject/pilotproject.html). This made an attempt to bring together space weather service providers and users in order to further develop the space weather service community in Europe, pushing forward the development, but mainly the implementation of existing space weather models in operational mode in Europe. The program incorporated 17 ESA co-funded Service Development Activities (SDAs) and a number of additional independently funded SDAs. These focus on a wide range of space weather user domains, providing services and products that address the needs of specific users through the Space Weather European Network - SWENET (http:// www.esa-spaceweather.net/swenet/). Currently, the SDAs provide data and services related to the effects of: (i) space weather on the ionosphere and on those technical fields affected by it, (ii) Geomagnetically Induced Currents (GIC) and other ground effects associated with space weather, (iii) space weather on onorbit spacecrafts and high flying aircraft. SWENET was added to previous ESA's operational tools available for space weather applications that include the Space Environment Information System (SPENVIS) operational software. SPENVIS was developed in 1996 and it is maintained since then through continuous upgrades to provide standardized access to most of the recent models of the hazardous space environment through a userfriendly web interface (http://www.spenvis.oma.be/).

The second Europe-wide space weather initiative came through the European Cooperation in Science and Technology (COST) framework (http://www.cost.eu/). In particular, an effort to coordinate space weather studies from a scientist's point of view with an eye on actual and potential applications was performed by COST Action 724 focusing in "Developing the scientific basis for monitoring, modelling, and predicting Space Weather" (Lilensten et al. 2004). The scientific progress in understanding and modeling space weather phenomena was presented in four topical reviews dealing with: (i) monitoring, modeling, and predicting solar weather (Messerotti et al. 2009), (ii) the radiation environment of the Earth (Vainio et al. 2009), (iii) solar wind disturbances and their interaction with geospace (Watermann et al. 2009b), and (iv) the upper atmosphere's response to space weather events (Belehaki et al. 2009a). One of the main recommendations of COST 724 pointed out the development and the online implementation of models for reliable space weather products (Belehaki \& Lilensten 2008). In parallel, the European COST 296 action "Mitigation of Ionospheric Effects on Radio Systems", continuing the studies of the previous COST 238, COST 251, and COST 271 actions, worked systematically on the development 
of an increased knowledge of the effects imposed by the ionosphere on practical radio systems and for the development and implementation of techniques to mitigate the deleterious effects of the ionosphere on such systems. An overview of COST 296 results designed for operational use was given by Stanislawska et al. (2009).

In these initiatives, one should add several national and European investments made the last decade in favor of operational developments in Europe. In this frame, various projects were launched to address specific problems. Relevant attempts include, to name some examples: DIAS (http:// dias.space.noa.gr) for ionospheric products and services relevant to $\mathrm{HF}$ communication users for the European region, SWACI (http://swaciweb.dlr.de/) in support of ionospheric and trans-ionospheric propagation purposes, and SEPEM project (http://sepem.aeronomie.be/) for creating models and tools to address current and future needs in modeling of the solar energetic particle environment. Substantial progress in European space weather operational modeling is foreseen through more recent activities undertaken within the Seventh Framework Programme (FP7) of the European Commission (http://cordis.europa.eu/fp 7/home en.html). An indicative but certainly not full list of such activities includes: SOTERIA that provides online tools for real-time monitoring and prediction of space weather (http://soteria-space.eu/index.php), COMESEP that develops tools for forecasting geomagnetic storms and solar energetic particle radiation storms (http://comesep. aeronomy.be/), ATMOP that works on the development of an advanced thermospheric model in support to Low Earth Orbit (LEO) predictions (http://www.atmop.eu/), SPACECAST that is designed to help protection of satellites on orbit by modeling and forecasting particle radiation (http://fp7-spacecast.eu/), and the EURISGIC that will produce the first European-wide realtime prototype forecast service of GIC in power systems (http://www.eurisgic.eu/).

A new platform for targeted space weather operations in Europe was formulated within the ESA Space Situational Awareness (SSA) Preparatory Programme that was authorized in November 2008 and formally launched on 1 January 2009. After an initial 3-year period up to 2011, full operational services are expected to be implemented in 2012-2019 (http:// www.esa.int/esaMI/SSA/index.html). As part of ESA's SSA, the Space Weather (SWE) Segment focuses on services for owners/operators of satellites in space and infrastructure on the ground. ESA's SWE services will enable end-users in a wide range of affected sectors to mitigate the effects of space weather on their systems, reducing costs and improving reliability (http://www.esa.int/esaMI/SSA/SEM0MNIK97G_0.html).

In the meantime, the COST ES0803 action in "Developing Space Weather Products and services in Europe" (Belehaki et al. 2009b) succeeded COST 724 in the coordination of space weather investigations in a wide-European level, with clear focus on applications (http://www.costes0803.noa.gr/). Having as primary goal to form an interdisciplinary network between European scientists dealing with different issues of geospace, as well as warning system developers and operators, COST ES0803 was designed to meet a set of secondary objectives including, (i) the assessment of the European potential in advanced space weather observational and modeling techniques and in reliable products and services, and (ii) the specification of new space weather products and services that best meet users' requirements. The Sub Group (SG) 1.3 "Improvement of operational models" was formulated within Working Group 1 "Advanced methods to model and predict space weather effects" framework at the meeting point of the two key directions.

The main objective of SG1.3 activities was to stimulate through a collaborative environment the effective upgrade of the existing operational modeling capabilities for space weather purposes in Europe. To this effect, the work that was performed within SG1.3 was based on COST ES0803 results on the identification of scientific advances, the assessment of existing space weather models, the review of existing space weather resources, and the analysis of the users' requirements.

This paper is the output of the COST ES0803/SG1.3 activities and it aims at presenting the advances achieved in the last 4 years in operational space weather modeling in Europe by the European research teams involved in the action. Typically, the operational space weather modeling capabilities are assessed in terms of three types of products: nowcasts, forecasts, and post-event analysis. This is also valid in the context of this paper with the following clarification: modeling efforts related to post-event analysis were not actually addressed within SG1.3. Nevertheless, for reasons of completeness we include here a short discussion of relevant European efforts. This overview is presented separately in Section 2 in relation to the space weather service domains that are also introduced in this section. The core section of this paper is Section 3 that describes the advances achieved by the European COST ES0803 community in space weather operational modeling for nowcasting and forecasting purposes. Section 4 attempts an overview of the improved capabilities, while this work concludes with Section 5.

\section{Operational post-event modeling according to space weather service domains}

Operational space weather models serve the purpose to support the assessment of the impact of space weather events on humans exposed to the space environment and on space-borne and ground-based technological systems. The SSA SWE segment identifies seven specific user domains. Within each of these domains several prototype services are specified which cover the range of operational support requested by the users (http://www.esa.int/esaMI/SSA/SEM0MNIK97G_0.html).

It is common to all SSA SWE services that they rely both on observations and a suite of operational models and tools which describe solar, interplanetary, and geospace environments. Geospace in this context means the space which is physically dominated by the Earth's magnetic and gravity fields. It is noteworthy to point out that the services require tools for forecasting, nowcasting, and retro-active modeling of the space environment, in contrast to the view that system operators are only interested in services which specify the present and future space weather conditions. But the interest in retro-active modeling of the environment has an obvious reason. Operators are not only interested in avoiding or mitigating effects to be expected from upcoming adverse space weather, they are also interested in understanding in sufficient detail effects experienced and damage suffered by their systems. Post-event analysis of space weather events is thus an important task for space and ground system operators.

Operational models for post-event analysis of space weather events were developed in different countries on different continents. In this section we limit the discussion to European models, in order to stay in line with the following sections which discuss recent developments of operational models by the 
European COST ES0803 space weather community. This limitation should not be misunderstood as a devaluation of nonEuropean models. European operational models in use for post-event analysis include, to name a few important examples: Salammbô (Bourdarie et al. 1996), a physics-based radiation belt flux model; SOLPENCO (Aran et al. 2006), physics-based simulations of gradual SEP event interplanetary fluxes and fluences; Magnetocosmics (http://cosray.unibe.ch/ laurent/ magnetocosmics/), simulation of cosmic ray particle propagation through the Earth's magnetosphere; Planetocosmics (http://cosray.unibe.ch/ laurent/planetocosmics/), simulation of the hadronic and electromagnetic interactions of cosmic rays with various planetary environments; DTM (Bruinsma et al. 2012), an empirical thermosphere density model. They can be used in combination with other models developed by specialized providers, as for instance: DICTAT (Martin 1991) available for internal charging analysis; GEMAT (http://reat.space. qinetiq.com/gemat/) for radiation effects on micro-electronics; MULASSIS (Lei et al. 2002) for multi-layered spacecraft shielding simulations.

The seven domains of the SSA SWE segment which rely on operational models are briefly discussed below, with emphasis on post-event modeling. Nowcast and forecast models are treated in subsequent sections.

Spacecraft design: Spacecraft designers require models to enable a retrospective analysis of a potential correlation between historical spacecraft anomalies and space environment conditions in order to take them into consideration in their design of future spacecraft and subsystems. Space weather threats to space systems are manifold, they cover directly damaging radiation effects including surface charging, internal charging, solar panel degradation, and indirect risks such as loss of radio contact (loss of control) and anomalous thermosphere drag. It is typical for this domain that environment models such as Salammbô or SOLPENCO are combined with spacecraft effect models to understand the cause-effect relation.

Spacecraft operation: Spacecraft operators likewise require models to enable analysis of potential correlation between historical spacecraft anomalies and space environment conditions, but in their case it is to understand spacecraft anomalies which were detected. The operational models used by spacecraft operators are largely the same as those used by spacecraft designers.

Human space flight: The requirements on modeling the impact of space weather radiation effects on humans under different conditions address flights in a space transport vehicle, extended stays at the International Space Station (ISS), and Extra Vehicular Activities. In these cases an assessment of the cumulative effect of long-term space radiation on the human body (specifically that of solar energetic particles) is of utmost importance. One way to measure this directly would be to have humans in space wear radiation dosimeters for different kinds of radiation without interruption but this is not the case in practice. However, the MATROSHKA experiment (Reitz \& Berger 2006) measures and archives the radiation dose onboard the ISS. It can be placed inside or outside the ISS. Therefore models are invoked to estimate the long-term radiation dose accumulation. Also here the operational models in use include some of the above-cited models (Salammbô, SOLPENCO, MULASSIS). Planetocosmics can be used in combination with SOLPENCO to propagate fluxes originating from solar energetic particle down to LEO orbits and compute deposited energies.
Launch operation: The launch vehicle carries its own operations control device which can work independently of the payload. The payload control unit and the various instruments are switched on only after the launch vehicle has separated from the payload. Similar to spacecraft operators, launch operators are interested in post-event analysis of potential radiation effects in sensitive launch vehicle electronics. A Single Event Effect caused by a single energetic particle, typically a highly energized proton, are of great concern (Messenger \& Ash 1997). The Magnetocosmics tool is used together with a statistical distribution of the interplanetary cosmic ray background to simulate cosmic ray particle propagation through the Earth's magnetosphere.

Space surveillance and tracking: This domain is included in the SSA SWE segment because tracking of space vehicles is affected by space weather. The principal space weather related effects of concern to surveillance radar operators are ionospheric and thermospheric effects. The TEC along the radar beam controls refraction and group delay of the radar signal. Variations of group delay and refraction (e.g., under conditions of storm-enhanced TEC) bear the consequence that the tracking accuracy suffers. Solar extreme ultraviolet (EUV) radiation and ionospheric electric currents deposit energy in the upper atmosphere which heats the neutral air, increases the scale height, and thus leads to enhanced neutral air density along the satellite trajectory and thus to increased drag and orbit change (Jacchia \& Slowey 1963). Post-event analysis is of lesser concern to surveillance radar operators, but it is nevertheless occasionally carried out. For that purpose observation-based semi-empirical models are used to compute partial TEC and thermospheric density.

Non-space System Operation: This domain addresses primarily ground-based technology, including resource exploitation, pipeline, and power line network operation, but also air traffic control. If electric power blackouts are observed, rapid geomagnetic variations can induce intense DC currents named GIC in electric power lines which may subsequently cause a power blackout. Similarly they can induce strong electric fields in the ground which change the pipe-to-soil electric potential of pipelines and thus may compensate the cathodic protection potential which is usually applied to prevent corrosion. Although accurate forecast of GIC is highly desirable, the analysis of past damages has been used extensively in order to fully understand the sequence of events that eventually lead to malfunctioning and in the worst cases to damage to the system. The modeling challenge encompasses the combination of models of the space environment, specifically of ionospheric and magnetospheric current systems, with models of the ground electric conductivity and engineering models of the power or pipeline networks (see Sect. 3.7). Air traffic companies are concerned about increased radiation exposure and degraded radio communication. In addition to models cited above in the pertinent domains, European Program Package for the Calculation of Aviation Route Doses - EPCARD (Mares et al. 2009) may be used to calculate the cosmic ray dose received during any user-specified commercial airline flight.

Trans-ionospheric radio link: Maintaining undegraded radio communication and precise navigation using radio waves play an important role in the domains Spacecraft Operation, Space Surveillance and Tracking, and Non-space System Operation. Trans-ionospheric Radio Link is different from the other domains of the SSA SWE segment in the sense that it is less 
important for post-event analysis and most important for nowcast and forecast purposes. The tools and models described in Sections 3.3-3.5 are as well applicable to retro-active modeling of the space plasma environment as far as radio wave propagation is concerned.

A demarcation line between models for post-event analysis, nowcasting and forecasting space weather events and effects does not generally exist because many models can do all of it, depending on the kind of data with which they are initiated. Several of the models for retro-active analysis of space weather events referred to in this section could fit also in the subsequent sections and vice versa.

\section{Operational modeling for nowcasting and forecasting products and tools}

For the effective upgrade of the existing operational modeling capabilities, COST ES0803 put emphasis on specific areas for which models could be adapted in order to be applicable in line with users' requirements. The upgrade was attempted through all possible means, from the improvement of existing codes and algorithms based on validation and verification tests, up to the introduction and the implementation of new models. To this effect, SG1.3 encouraged pre-existing collaboration scenes on related activities and triggered new ones. Most of the proposed activities succeeded in yielding applicable results within the action's lifetime, while few are still in progress, being able to provide promising results in the future. A comprehensive overview of the models addressed by SG1.3 team is presented below. The models are classified in seven groups that cover the broad range of space weather's prediction requirements from the Sun to the Earth within operational environments.

It may be important to make clear that the focus on COST ES0803 models in this section is tightly related to the objectives of this paper and does not imply by any means that the models discussed below are in principle the only ones available within each category in Europe or worldwide. Indeed, there are many relevant space weather modeling efforts, coming from outside COST ES0803 community that could fit into this discussion. However, due to the wide range of the related research and application areas, a representative but still fair report of the existing initiatives in each category would require a totally different treatment that is beyond the scope of this paper.

\subsection{Solar weather predictions}

\subsubsection{Bradford's Automated Solar Activity Prediction System for solar flare predictions (http://spaceweather.inf.brad.ac.uk/asap)}

The Automated Solar Activity Prediction (ASAP) System is a real-time technology for processing satellite images to predict extreme solar flares. ASAP integrates state-of-the-art image processing with machine learning technologies for its operation. Hence ASAP's operation is based on the successful integration of two modules: an imaging module and a machine learning module.

The imaging module is responsible for processing multiwavelength solar images and applying various tasks for the detection of the solar disk, removing the limb darkening effect, filtering, detection of solar features, extracting features, grouping and classifying sunspots, etc.
The machine learning module explores various solar catalogs/images to associate solar features with solar events using data mining technique. This knowledge is represented using computerized learning rules. ASAP's predictions are generated by comparing the feature patterns detected by the imaging module with the knowledge extracted by the machine learning module. The major publications covering the development of all ASAP's technologies can be found at http://spaceweather.inf.brad.ac.uk.

ASAP is currently working in real time and is integrated with the SWENET, which is supported by the ESA, as a SDA http://www.esa-spaceweather.net/sda/asap/. It is also integrated with NASA's Community Coordinated Modeling Center (CCMC), where it is currently operational at http://iswa.gsfc. nasa.gov/iswa/iSWA.html. ASAP's predictions are also available on the group website at http://spaceweather.inf.brad.ac.uk.

Some of the recent developments surrounding the ASAP system and its supporting technologies can be summarized below:

- ASAP's team at University of Bradford carried out joint research work with Trinity College Dublin (Ahmed et al. 2013) to develop novel machine-learning and feature-selection algorithms to combine two of the recent developments in solar physics and space weather, which are ASAP and the Solar Monitor Active Region Tracker (SMART) system (Higgins et al. 2011). SMART extracts, characterizes, and tracks the evolution of active regions across the solar disk using line-of-sight magnetograms and a combination of image processing techniques. In this work data mining and spatiotemporal association algorithms were developed to associate MFs with flares in order to differentiate flaring and non-flaring MFs and enable the application of machine-learning algorithms for flares prediction. The prediction performance is assessed using standard forecast-verification measures and compared with the prediction measures of ASAP (Ahmed et al. 2013).

- ASAP's team at University of Bradford carried out joint research with Royal Observatory of Belgium (ROB), Glasgow University, and Trinity College Dublin (Verbeeck et al. 2013). The aim of this work was to compare the performance of established solar imaging systems (ASAP, Spatial Possibilistic Clustering Algorithm (SPoCA), Sunspot Tracking and Recognition Algorithm, and SMART) when processing SDO data. The overall detection performance of each algorithm is benchmarked against NOAA and Solar Influences Data Analysis Centre (SIDC) catalogs using various feature properties such as total sunspot area and the number of features detected.

- ASAP's team at University of Bradford introduced a fast fuzzy-based solar feature detection system for processing SDO/AIA images using fuzzy rules to detect coronal holes and active regions (Colak \& Qahwaji 2013). This system generates filling factors (ratio of area of solar feature to area of rest of the solar disk) for active regions and coronal holes. These filling factors are then compared to $\mathrm{SDO} / \mathrm{EVE} / \mathrm{ESP}$ irradiance measurements. Correlation between active-region filling factors and irradiance measurements is found to be very high.

- ASAP's team at University of Bradford introduced a new method for the 3D visualization of active regions and sunspots that are detected from SOHO/MDI magnetogram and continuum images (Colak et al. 2011). 
This technology will be used to create a visual solar catalog. Because of the difficulty in providing a full description of data in text-based catalogs, it can be more effective to search these 3D solar feature models in visual solar catalog environment. This catalog could provide advanced interpretation of solar images, since it would enable us to extract data embedded in various solar images and visualize it simultaneously.

\subsubsection{SPoCA-suite for Near-Real-Time detection and tracking of Active Regions and Coronal Holes on SDO-AIA data}

The SIDC team at the ROB has developed the SPoCA-suite, a set of algorithms that is able to detect, extract, and track active regions and coronal holes on EUV images (http://sdoatsidc.oma.be/web/sdoatsidc/SoftwareSPoCA). The detection algorithm runs in near real-time on SDO-AIA images at LMSAL and produces entries to the Heliophysics Event Knowledgebase - HEK (http://www.lmsal.com/hek/ hek isolsearch.html), including statistics on intensity, bounding box, but also a representation of the boundary in terms of chain code (Delouille et al. 2012).

Active regions are the main source of solar flares whereas coronal holes are associated with expanding open magnetic fields and the acceleration of the high-speed solar wind. For space weather purpose it is therefore important to locate precisely both active regions and coronal holes. The SPoCA-suite is based on a fuzzy clustering that has been custom-designed to get optimal results on EUV images. It can extract and track active regions as well as coronal holes. The algorithm was applied on the archive of SOHO-EIT data from 1997 till 2005 to get relative proportion of Active Regions, Coronal Holes, and Quiet Sun covering the Sun during the solar cycle 23 (Barra et al. 2009).

In work in progress, we applied the coronal hole detection and tracking algorithm on a SDO-AIA $19.5 \mathrm{~nm}$ dataset ranging from June 2010 until October 2011. The coronal hole detection was validated by cross-checking with SDO-HMI magnetograms. Figure 1 shows an example of coronal hole map obtained with SPoCA. We also investigated the relationship between position of coronal holes and the properties of resulting high-speed solar stream.

\subsubsection{The UMASEP for forecasting SEP events http://spaceweather.uma.es/forecastpanel.htm}

UMASEP system makes real-time predictions of the time interval within which the integral proton flux is expected to meet or surpass the SWPC SEP threshold of $J$ $(E>10 \mathrm{MeV})=10 \mathrm{pr} \mathrm{cm}^{-2} \mathrm{sr}^{-1} \mathrm{~s}^{-1}$ and the intensity of the first hours of SEP events. This forecaster analyzes flare and near-Earth space environment data (soft X-ray, differential and integral proton fluxes). The current version of UMASEP (Núñez 2011) has been functioning since 2010 and its real-time forecasts are currently downloaded every $5 \mathrm{~min}$ from users' space weather systems, such as the European Space Weather Portal (http://www.spaceweather.eu/en/forecast/uma_sep) and the integrated Space Weather Analysis (iSWA) system of NASA (http://iswa.ccmc.gsfc.nasa.gov/iswa/iSWA.html).

The UMASEP forecaster is based on a dual-model approach. The purpose of the first model is to identify precursors of well-connected events by empirically estimating the

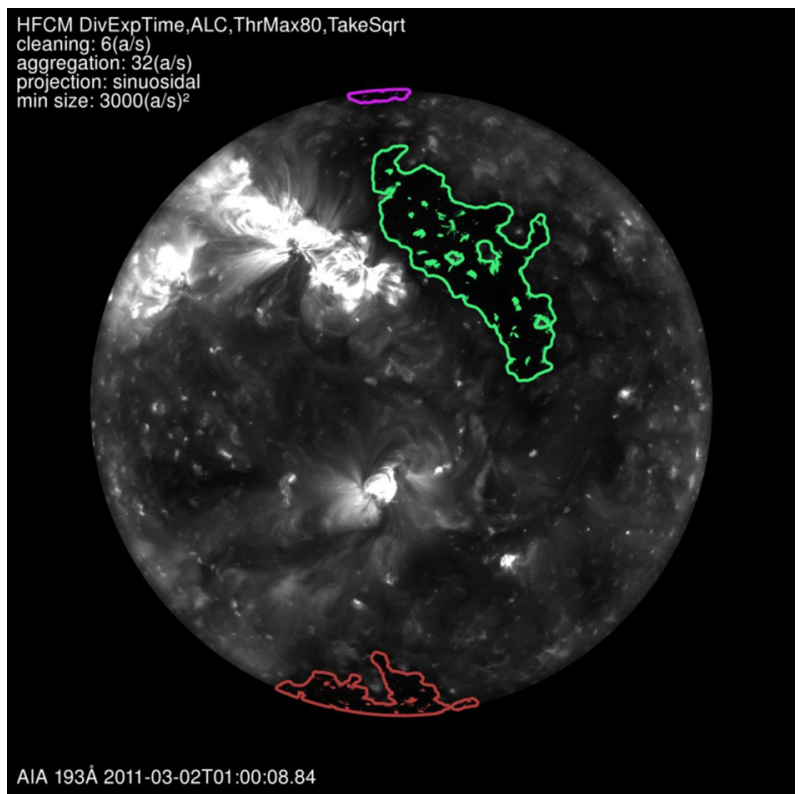

Fig. 1. Example of a coronal hole map overlaid onto the original $193 \AA$ AIA image (cropped at 1 solar radius) taken on March 2, 2011 at 01:00:08. The corresponding segmentation algorithm uses Fuzzy C-Means.

magnetic connectivity from the associated CME/flare process zone to the near-Earth environment and identifying the flare temporally associated with the phenomenon. To recognize a possible magnetic connection, UMASEP searches for a cause-consequence pattern, which consists of a persistent lag correlation between the derivative of the soft X-ray flux and at least one of the derivatives of the differential proton fluxes ( $9 \mathrm{MeV}<E<500 \mathrm{MeV}$, measured at $1 \mathrm{AU}$ by all the available GOES satellites). If a magnetic connection is recognized and it is followed by a C7 flare or higher, this model predicts a well-connected SEP event. The goal of the second model is to identify precursors of poorly connected events by using a regression model that checks whether the differential proton flux's behavior is similar to that in the beginning phases of previous historically poorly connected SEP events, and thus deduce similar consequences. An additional module applies a higher-level analysis for inferring additional information about the situation by filtering out inconsistent preliminary forecasts and estimating the intensity of the first hours of the predicted SEP events. This high-level module periodically retrieves solar data and, in the case of the well-connected events, automatically identifies the associated flare and active region. Figure 2a shows the forecast outputs after analyzing an historical event and Figure $2 \mathrm{~b}$ shows the forecasts during real-time operations on March 8 and 21, 2011.

UMASEP has been evaluated with historical data and in real-time operations. Núñez (2011) presents the evaluation of UMASEP with historical data of solar cycles 22 and 23, obtaining a probability of detection (POD) of all SEPs of $80.72 \%$ $(134 / 166)$, a false alarm rate (FAR) of $33.99 \%(69 / 203)$, and an average warning time (AWT) of $5 \mathrm{~h} 10 \mathrm{~min}(1 \mathrm{~h} 5 \mathrm{~min}$ for well-connected events and $8 \mathrm{~h} 28$ min for poorly connected events). The AWT is the temporal distance between the time when the prediction is issued and the time when the integral proton flux meets or surpasses the SWPC SEP threshold. The NOAA/SWPC SEP list was used for obtaining the official SEP start times. Nuñez (2011) also presents a comparison with 

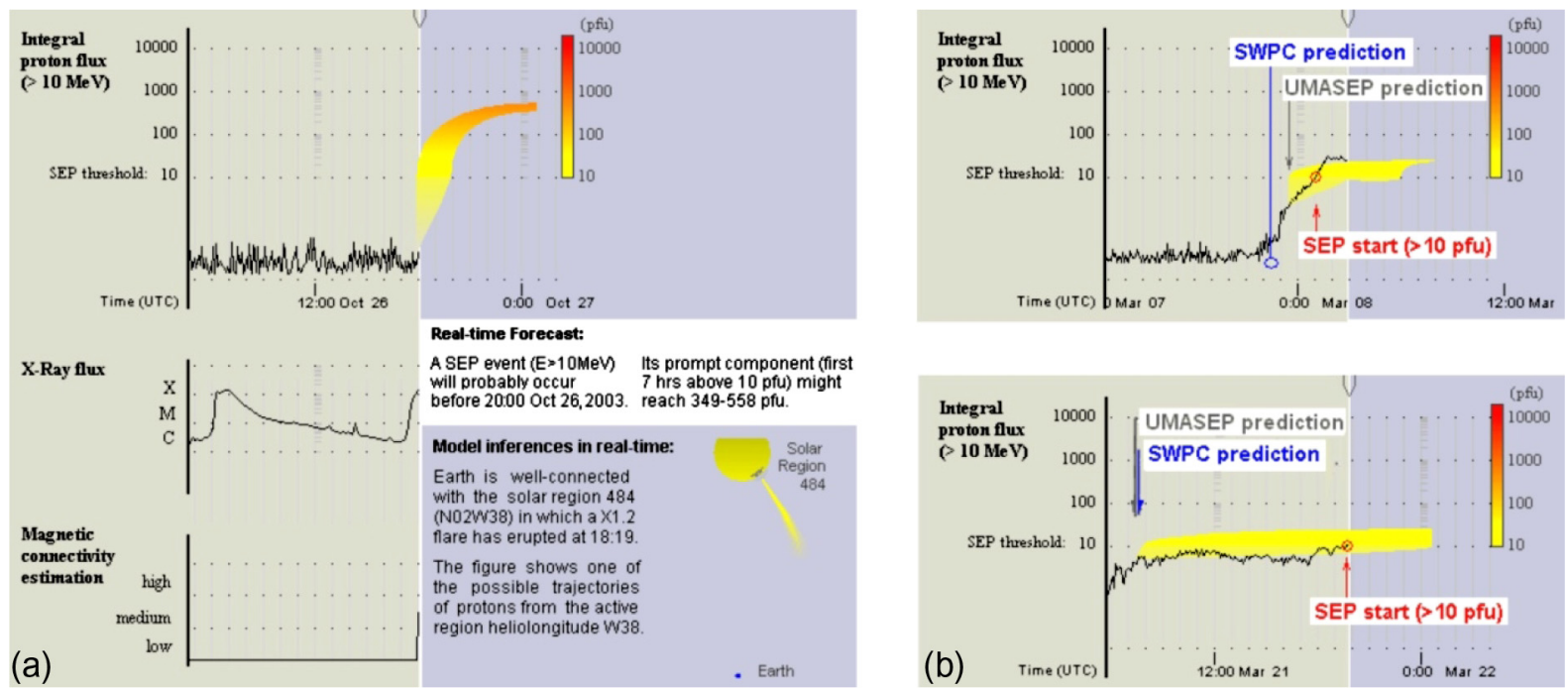

Fig. 2. (a) The UMASEP output after processing historical data from October 26, 2003, during which a well-connected event occurred. The small upper-right chart of Figure $2 \mathrm{a}$ shows the posterior evolution of the integral proton flux for this event, demonstrating that the forecast was successful (adapted from Figure 4 in Núñez 2011). (b) Two successful forecasts issued by UMASEP while processing real-time data during March 8, 2011 (top) and March 21, 2011 (bottom). The two images on the right, taken from the historical database of NASA's iSWA system, were also used to indicate the times of the forecasts of the UMASEP and NOAA/SWPC services.

other systems, showing that UMASEP outperforms current automatic forecasters in predicting $>10 \mathrm{MeV}$ SEP events. UMASEP's performance during the current solar cycle 24 rendered similar results: POD of $81.8 \%(9 / 11)$, FAR of $30.8 \%(4 / 13)$, and AWT of $5 \mathrm{~h} 27 \mathrm{~min}$. By taking into account the current solar cycle (from January 1, 2008, to March 10, 2012) a preliminary comparison between UMASEP, an automatic service, and the NOAA/SWPC SEP forecasting service, which issues warnings based on the analysis made by human forecasters aided by computerized models (Balch 2008), shows that: both services have similar FAR; NOAA/SWPC has a better performance in POD, and UMASEP has a better performance in AWT.

During the revision of this manuscript, a new version of UMASEP was released. In addition to predicting $>10 \mathrm{MeV}$ events, this new version also predicts SEP events with energies greater than $100 \mathrm{MeV}$. The POD of the new $>100 \mathrm{MeV}$ forecasts is $82.6 \%$ and the FAR is $36.6 \%$, taking into account data of solar cycles 23 and 24 (until January 2013). The average of the warning times is $58 \mathrm{~min}$; however, there were several very energetic ground level events (GLE) that could be predicted with very low warning times, ranging from 5 to $20 \mathrm{~min}$.

\subsection{Geomagnetic predictions}

\subsubsection{The UAH-Space Weather Service - warnings for geomagnetic disturbances}

The UAH-Space Weather Service (UAH-SWS) at http:// www.spaceweather.es/ has been developed based on scientific models published in international journals by researchers of the UAH (Cid et al. 2008; Saiz et al. 2008; Aguado et al. 2010). It is a double service: (1) it offers a warning of severe geomagnetic disturbances and (2) it provides an estimation of the time remaining for the magnetosphere to recover quiet time conditions. The service is available free of charge $24 \mathrm{~h}$ a day, 365 days a year, both online and by email after subscription for space weather alerts.
The warning from UAH-SWS consists in a $\delta$ function (true/ false): "true" when a $\Delta D s t$ larger than $50 \mathrm{nT}$ in an hour is expected, "false" otherwise. The warning code is written in IDL based on the model introduced by Saiz et al. (2008). There is only one input for the warning code: the IMF $z$-GSM component, which is downloaded automatically via ftp from NOAA. The UAH server connects to NOAA server every minute and then runs the code again. The main success of the UAH-SWS is not only the accuracy in the forecasting process, but also the science behind the code, which is a great improvement in the task of understanding the Sun-Earth connection: variations in $\mathrm{Bz}$ IMF are related to large geomagnetic disturbances (Cid et al. 2008).

The warning code has been working since 2008, but due to the solar minimum, the first warning was produced on September 26, 2011 at 13:25 UT (Fig. 3). That day Kyoto web page showed a drop on Dst from $+3 \mathrm{nT}$ at 16 UT down to -53 at 17 UT, reaching a peak value of -117 on September 27 at 00 UT. This alert allowed checking and improvement of some aspects in the service. Just as an example, it can be cited that on September 26, the users subscribed to the service received one e-mail per minute for more than $2 \mathrm{~h}$. This problem has now been solved and only one e-mail is sent for one event. There was also a delay in the warning from what obtained from the code. This is still under investigation.

Concerning the service on the prediction of the magnetosphere's recovery, it provides a graph with the theoretical expectations from the hyperbolic model introduced by Aguado et al. (2010) plotted together with the Dst index from Kyoto, as soon as Dst goes below $-100 \mathrm{nT}$. The code updates the graph every hour, in accordance with the resolution of the Dst index and theoretical expectations are computed until $48 \mathrm{~h}$ after the peak value on the index.

\subsubsection{The Hybrid Dourbes $K$ model for nowcasting and forecasting the $K$ index}

Kutiev et al. (2009a) developed the Hybrid Dourbes $K$ (HDK) model, an empirical model for nowcasting and forecasting a 
(a)

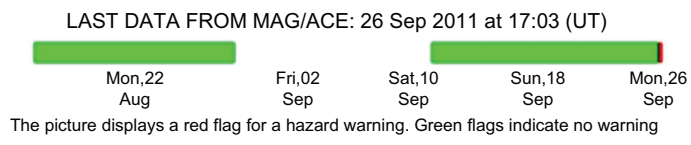

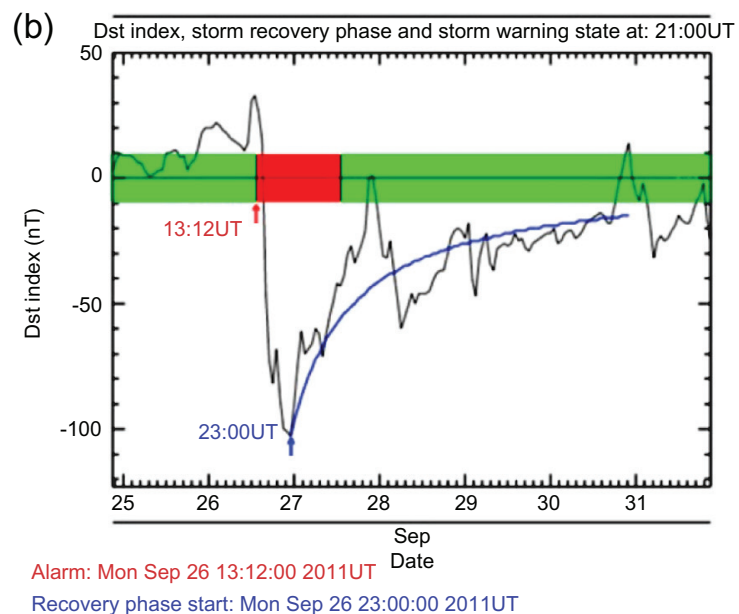

Fig. 3. (a) Screenshot of the first warning provided by the UAH-SWS in real time. (b) New appearance of a screenshot of the first warning after improving the aspect of the output.

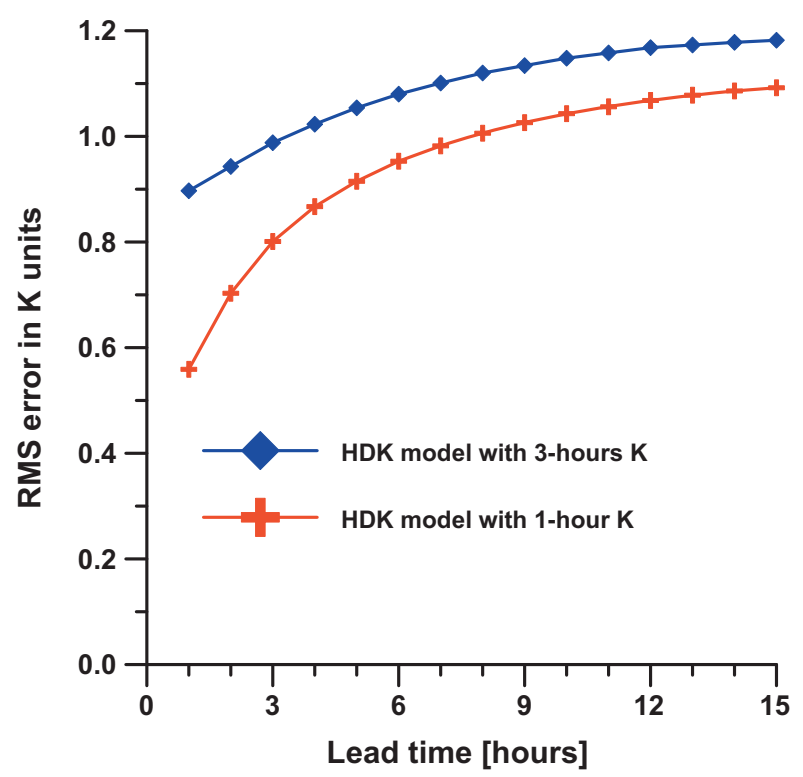

Fig. 4. The HDK prediction error obtained by using 3-h $\mathrm{K}$ (blue line) and the hourly interpolated $K d$ values (red line) (after Kutiev et al. 2009a).

quantity, which is a proxy to the geomagnetic $K$ index. HDK is based on the combined use of solar wind parameters and ground-based magnetic data. The model implements the previously developed solar wind based MAK (Muhtarov-AndonovKutiev) model (Andonov et al. 2004), calibrating its values with magnetogram-derived $K$ index.

The MAK model provides a proxy of $K p$ denoted as $K s w$, while that provided by Dourbes Observatory is denoted as $K d$. The HDK nowcast model predicts the quantity $K d f$, obtained by solar wind based $K s w$ and corrected with a combination of differences between several past values of $K d$ and $K s w$. The HDK is the first model $K$ which provides analytical formulas for nowcasting and forecasting $K$ index by combining ground-based magnetic and solar wind data. The model error for nowcasting is $0.38 \mathrm{KU}$, or nearly twice less than that of the MAK model. Forecasting $6 \mathrm{~h}$ ahead carries an error of $1.0 \mathrm{KU}$, while for the first $1 \mathrm{~h}$ the error is $0.58 \mathrm{KU}$ only. In Figure 4, the blue line represents the prediction error obtained by using $3-\mathrm{h} K$ values and the red line represents the prediction error obtained by using the hourly interpolated $K d$ values. HDK model is implemented in the operational forecasting software of the Royal Meteorological Institute, Belgium (http://gpsweather.meteo.be/geomagnetism). As input it uses the online $K$ index obtained from Dourbes magnetometer and solar wind parameters from ACE satellite.

\subsection{Satellite environment predictions}

\subsubsection{Topside Sounder Model Profiler-assisted Digisonde (TaD) for the reconstruction of the electron density profiles up to geosynchronous heights}

A model-assisted technique for the reconstruction of the topside electron density profile to heights above the transition height was recently developed (Kutiev et al. 2010) following up a series of successive scientific advances (e.g., Belehaki et al. 2006a; Kutiev et al. 2006, 2009b; Kutiev \& Marinov 2007). The proposed $\mathrm{TaD}$ technique connects topside empirical modeling with Digisonde data. In particular, TaD exploits the results of the Topside Sounder Model Profiler (TSMP) that provides the $\mathrm{Ne}$ profiles above the F2 layer peak height $(\mathrm{hmF} 2)$ on a global scale, as a function of the geomagnetic latitude, day of year, local time, solar flux F10.7, and $K p$ once the F2 layer maximum density $(\mathrm{NmF} 2)$, the peak density height (hmF2), and the scale height $(\mathrm{Hm})$ at its lower boundary are provided (Kutiev \& Marinov 2007). For this purpose, TaD succeeded to apply TSMP to the electron density profiles obtained by ground-based Digisondes. The TaD profiler was validated using topside profiles reconstructed from IMAGE/RPI plasmagrams, as well as GNSS-TEC and CHAMP-derived TEC estimates (Belehaki et al. 2010).

Since its development, TaD received further upgrade through improvements to the reconstruction technique and reformulation of the model's expressions. The improved TaD profiler was subject to extensive validation tests using Incoherent Scatter Radar (ISR) profiles obtained at Malvern site and GNSS-TEC estimates. The results indicate a model error of 3 TECU, which is close to the measurement (GNSS) error (Belehaki et al. 2011; Belehaki et al. 2012).

Going one step further, the operational capabilities of the $\mathrm{TaD}$ algorithm were explored through its online implementation 


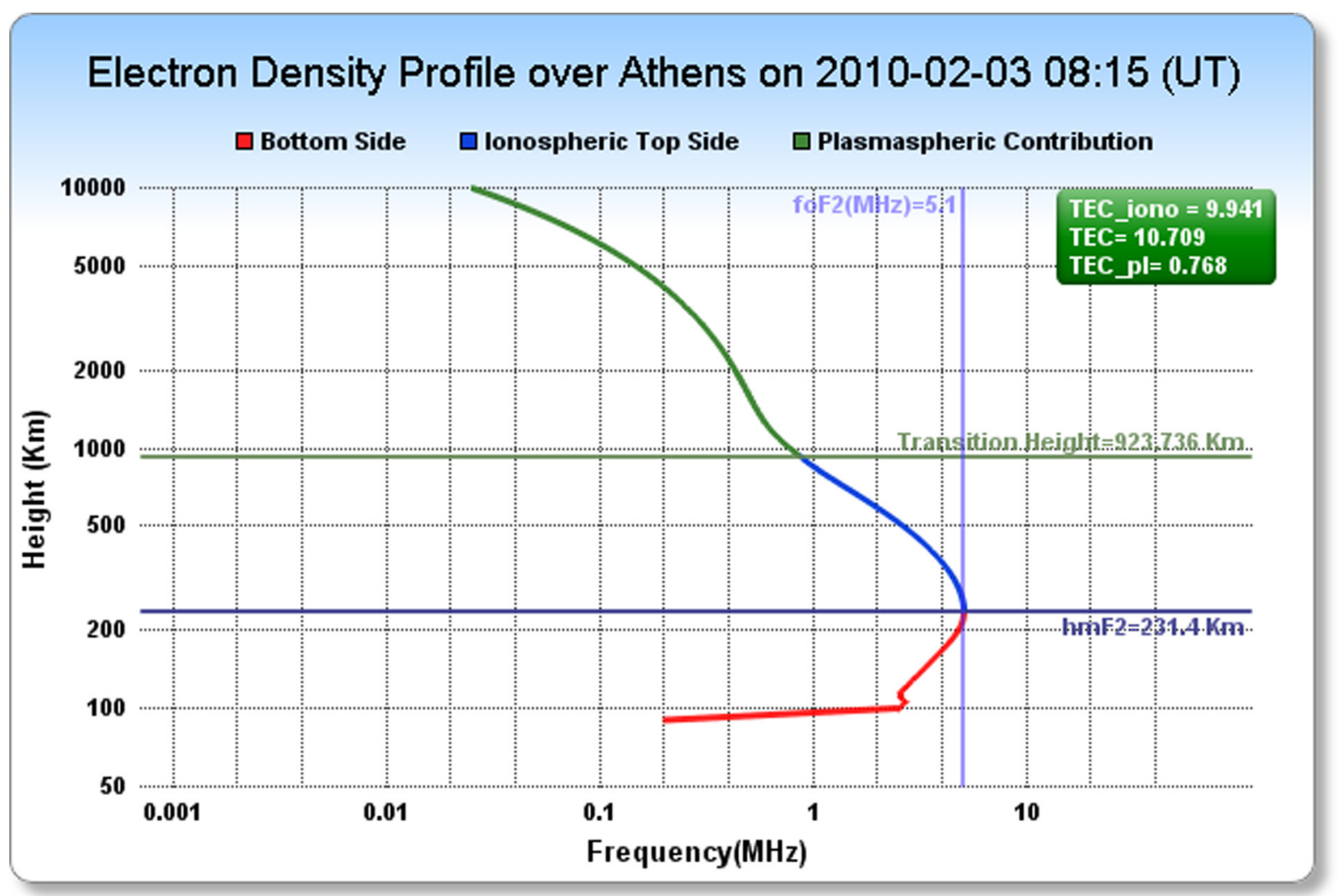

Fig. 5. Example of the TaD-reconstructed electron density profiles over Athens and the related estimations (http://www.iono.noa.gr/ ElectronDensity/EDProfile.php). Bottomside profile: retreived from SAO data taken by the Athens Digisonde in real time (red curve). Topside profile: TaD model output (blue curve). Plasmaspheric profile: TaD model output (green curve). TEC-iono (in TECU): the integrated electron density from $90 \mathrm{~km}$ up to transition height. TEC (in TECU): the integrated electron density from $90 \mathrm{~km}$ to $20000 \mathrm{~km}$. TEC pl (in TECU): the integrated density from the transition height up to $20000 \mathrm{~km}$ (plasmaspheric contribution).

to the Athens digisonde data. Some results are demonstrated at http://www.iono.noa.gr/ElectronDensity/EDProfile.php. An example of the TaD-reconstructed electron density profiles over Athens and the related estimations is presented in Figure 5. It is clear that the real-time implementation of the TaD over each Digisonde location can offer a variety of applications, especially over regions where dense networks of Digisondes operate (e.g., the DIAS system).

Next, a special procedure that adjusts $\mathrm{TaD} \mathrm{Ne}$ integral by varying the scale height factor in order to equalize it with the corresponding measured GPS-TEC value was envisaged. This procedure, which improves significantly the reconstructed $\mathrm{Ne}$ profile and has been proven to be very important for the application of $\mathrm{TaD}$ in an operational environment, has currently been implemented in the operational version of the model (Kutiev et al. 2012).

At this point, it is worth mentioning two COST ES0803 modeling activities, which even if they are not currently supported by operational or semi-operational prototype versions, have the potential to support valuable space weather products and services under further development. These include:

(i) Development of a new method for the derivation of thermospheric parameters from routine ionospheric observations (Mikhailov et al. 2012; Mikhailov et al. 2013). In particular, the new method combines electron density profiles observed by ISR or Digisondes with modeled results to extract a set of basic thermospheric parameters including: exospheric temperature Tex, $\mathrm{S}-\mathrm{Tn}(\mathrm{h})$ shape, atomic and molecular oxygen concentration, molecular nitrogen concentration, and vertical plasma drifts. This work is in progress, suggesting an alternative solution for thermospheric monitoring purposes.

(ii) Development of a new model to predict fluxes of relativistic electrons at geosynchronous orbit. This is based on the analysis of ULF wave spectra measured by ACE magnetometer, and ULF oscillations measured by GOES magnetometers at geosynchronous orbit and by groundbased magnetometers distributed globally and it combines ground-based $\mathrm{PiB}$ geomagnetic pulsations with global ULF oscillations of Pc5 type (Degtyarev et al. 2009; Degtyarev et al. 2010; Potapov and Polyushkina 2010).

\subsection{Communications predictions}

\subsubsection{The real-time updating of the Simplified Ionospheric Regional Model (SIRMUP)}

SIRMUP (Zolesi et al. 2004; Tsagouri et al. 2005) is implemented online to provide nowcasting ionospheric products and services for the European region through DIAS system (Belehaki et al. 2006b, 2007) and for the central Mediterranean area through the - Geomagnetic Indices Forecasting and Ionospheric Nowcasting Tools (GIFINT) services (http:// gifint.ifsi.rm.cnr.it/) that is integrated with the SWENET. 

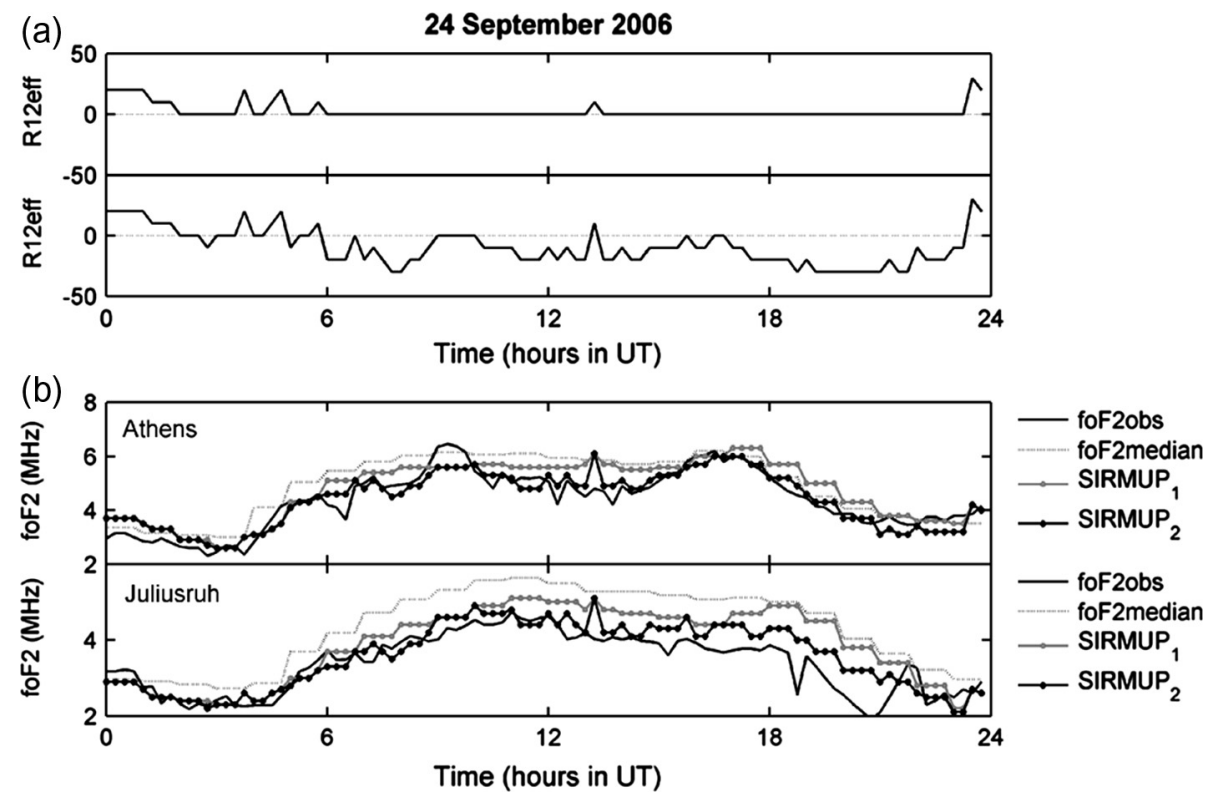

Fig. 6. (a) R12eff estimates obtained considering only positive values (from 0 to 200) for its derivation (first panel) and full ranged (from -30 up to 200) R12eff (second panel) for September 24, 2006. (b) foF2 observations and monthly median estimates in comparison to SIRMUP 1 (old) and SIRMUP 2 (improved) predictions for Athens and Juliusruh (after Tsagouri et al. 2010).

In SIRMUP, the real-time values of foF2 at one location are determined from the SIRM model (Zolesi et al. 1993) by using the effective sunspot number, R12eff, instead of $R_{12}$. R12eff is calculated through the comparison of SIRM estimates with actual measurements. The method of determining R12eff was introduced by Houminer et al. (1993) and the main steps of the methodology are summarized as follows: R12eff is chosen to give the best fit between model calculation and actual measurements obtained from a grid of ionosondes located in the mapping area, referred to as reference stations. Most critical point to the derivation of R12eff is the number $n$ of stations that provide real-time measurements at the same time. In the Houminer et al. (1993) method this number should be atleast 4

Of crucial importance are also the time resolution and the range of $R 12$ eff values. As real-time observations are available every $15 \mathrm{~min}$ in DIAS, the R12eff is also calculated with 15 min time resolution. The high time resolution in combination with the fact that ionospheric conditions are highly absorbed in its derivation, keep off R12eff's concept from the original $R_{12}$ that is a solar activity index, and bring it closer to a potential ionospheric activity index. As that, R12eff should be able to capture severe ionospheric disturbances (greater than $50 \%$ of the median conditions) and therefore the range of the permissible values should be carefully considered. Preliminary tests of SIRMUP's performance indicated problems deduced from the standard scale of $R_{12}$ at solar minimum conditions for which $R_{12}=0$ marginally reflected median conditions. It was clear that the R12eff scale should be expanded toward negative values. Empirical tests that were carried out near solar minimum yield to minimum value of R12eff equal to -30 . The improvements ensure better performance of the SIRMUP during solar minimum conditions (Tsagouri et al. 2010). Figure 6 provides an example of the achieved improvement, while Figure 7 provides an example of the DIAS nowcasting foF2 maps obtained under negative R12eff conditions.

\subsubsection{Solar Wind driven autoregression model for Ionospheric short-term Forecast}

A new ionospheric forecasting algorithm suitable for operational applications, the Solar Wind driven autoregression model for Ionospheric short-term Forecast (SWIF), was recently introduced (Tsagouri et al. 2009; Kutiev et al. 2013). SWIF combines historical and real-time foF2 observations with IMF parameters obtained in real time at the L1 point from NASA/ ACE spacecraft. This is achieved through the cooperation of an autoregression forecasting algorithm, called Time Series AutoRegressive - TSAR (Koutroumbas et al. 2008), with the empirical Storm-Time Ionospheric Model - STIM (Tsagouri \& Belehaki 2008) that formulates the ionospheric storm-time response based on IMF input. SWIF is able to provide ionospheric foF2 forecasts as well as alerts and warnings for upcoming ionospheric disturbances for the middle latitude ionosphere (Tsagouri et al. 2009). SWIF is implemented online in DIAS and provides alerts and warnings for upcoming ionospheric disturbances as well as ionospheric forecasts up to $24 \mathrm{~h}$ ahead for the European region.

\subsubsection{Geomagnetically Correlated Autoregression Model for foF 2 forecast}

Muhtarov et al. (2002) introduced the Geomagnetically Correlated Autoregression Model (GCAM) for the short-term forecasting of the foF2. GCAM incorporates the cross-correlation between the foF 2 and the ap index into the autocorrelation analysis. It is an extrapolation model based on weighted past data and the model's predictions are driven by (i) current and recent past foF2 measurements and records of a geomagnetic activity index, (ii) estimates of the reference ionosphere, and (iii) prediction of a geomagnetic activity index for each hour of the prediction period. A synthetic geomagnetic activity index, G, of hourly resolution based on the $A p$ index was also introduced 


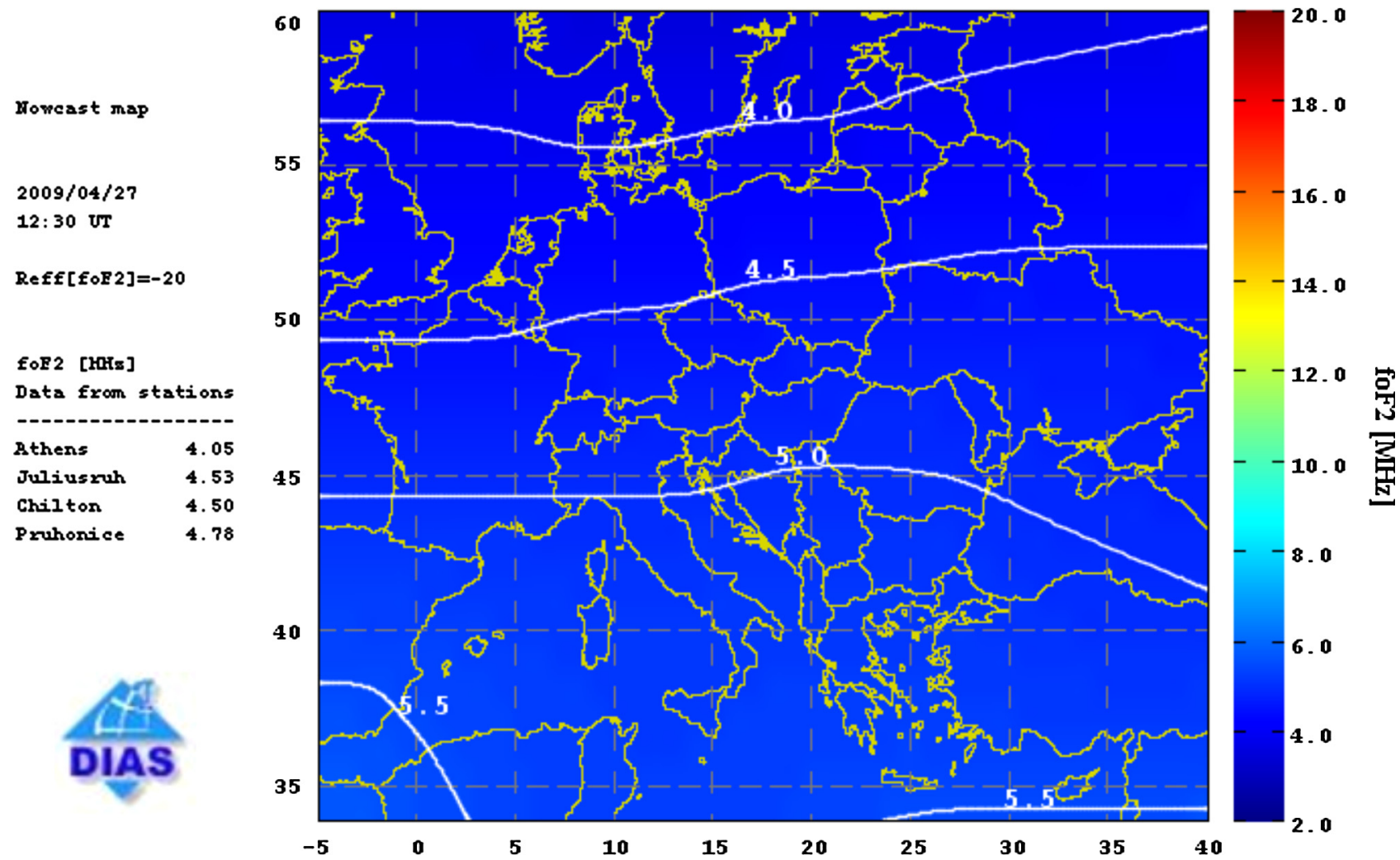

Fig. 7. DIAS nowcasting foF2 maps obtained on April 27, 2009 at 12.30 UT. The R12eff estimation, as well as the stations that this estimation was based on, is provided on the left (http://dias.space.noa.gr).

by Muhtarov et al. (2002) to ensure forecasting ability of the model. In particular, the index $\mathrm{G}$ is extracted from the daily $A p$ index for which a 45-day prediction is issued by the SWPC of NOAA. The GCAM model is currently implemented in the DIAS system to provide ionospheric forecasts up to $24 \mathrm{~h}$ ahead for the European region. For the implementation of GCAM in DIAS system, model parameters were calculated for each DIAS location by using ionospheric observations from at least one and a half solar cycle (Tsagouri 2011).

The performance of both the SWIF and the GCAM models was investigated in the central European region with a metricsbased evaluation procedure proposed within SG 1.2 of COST ES0803 (Tsagouri 2011). The results demonstrate significant (greater than 10\%) improvement over climatology and persistence of both models performance and all prediction steps under ionospheric storm conditions.

The accuracy of the two models was also determined for all possible conditions in terms of the mean relative error. The accuracy depends on the prediction step, the level of the ionospheric activity, and the latitude of the observation point. It is relatively small (10-13\%) for predictions provided $1 \mathrm{~h}$ ahead and may reach $30 \%$ at middle to high latitudes for high ionospheric activity level and predictions provided $24 \mathrm{~h}$ ahead.

\subsubsection{The short-term Ionospheric Forecasting Empirical Regional Model (IFERM)}

IFERM was recently developed to predict the state of the foF2 critical frequency under different geomagnetic conditions (Pietrella 2012). IFERM is based on 13 short-term ionospheric forecasting empirical local models (IFELM) developed to predict foF2 at 13 ionospheric observatories scattered around the European area. The forecasting procedures were developed using for each observatory the following data: hourly measurements of the foF2; hourly quiet time reference values of the foF2 (foF2QT); hourly time weighted accumulation series derived from the geomagnetic planetary index $a p,(a p(\tau))$. The index $\operatorname{ap}(\tau)$ takes into account the recent history of the geomagnetic activity, where $\tau$ is a 3 -h attenuation multiplier $(0 \leq \tau<1)$ that determines how $\operatorname{ap}(\tau)$ will depend on the past history of the $a p$ index (Wrenn 1987). The bigger the value of $\tau$, the more dependence $a p(\tau)$ will have upon its history. The use of $a p(\tau)$ in place of the geomagnetic index ap improves the ionospheric forecasting, as it is demonstrated by Wrenn \& Rodger (1989) and Wu \& Wilkinson (1995).

The forecasting maps obtained with the foF2 values predicted in the IFELM operating simultaneously were analyzed to assess IFERM performance on the spatial regional scale (Fig. 8 shows an example). From this examination it has emerged that there are very large areas located at middle-high latitudes $\left(50^{\circ}<\lambda<60^{\circ}\right)$ and high latitudes $\left(\lambda \geq 60^{\circ}\right)$ where the foF 2 predictions match quite faithfully the foF 2 measurements, since the difference between the foF2 measurements and the foF 2 predictions is less than 0.4 or $0.8 \mathrm{MHz}$ depending on the observation area (Pietrella 2012). Consequently IFERM can be used for generating short-term forecasting maps (up to $3 \mathrm{~h}$ ahead) of the foF2 over the European area.

\subsubsection{The Neustrelitz Peak Density Model (NPDM)}

The NPDM represents an empirical modeling approach that allows determining global NmF2 with a limited number of model coefficients (Hoque \& Jakowski 2011). The nonlinear approach needs 13 coefficients and a few empirically fixed parameters for describing the NmF2 dependencies on local time, geographic/geomagnetic location, and solar irradiance 

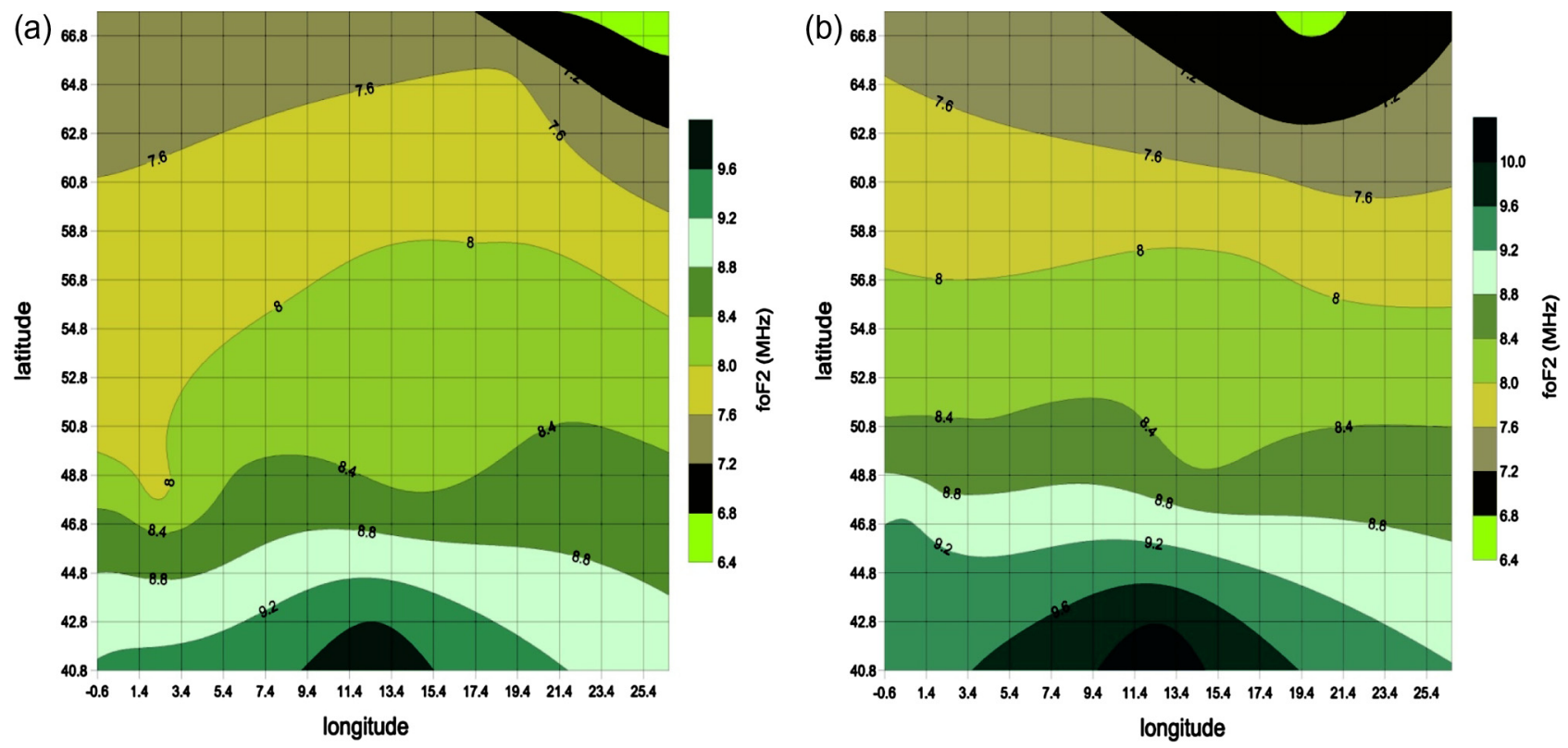

Fig. 8. (a) Map obtained from foF2 measurements and (b) forecasting map for foF2 one hour in advance generated using the IFERM model on 11 September 1991 at 13:00 UT under disturbed geomagnetic conditions $(a p(\tau=0.8)=26.3 ; \operatorname{ap}(\tau=0.9)=27)($ after Pietrella 2012).

and activity. The model approach is applied to a vast quantity of global NmF2 data derived from GNSS radio occultation measurements provided by CHAMP, GRACE, and COSMIC satellite missions and about 60 years of processed $\mathrm{NmF} 2$ data from 177 worldwide ionosonde stations. The model fits to these input data with the same standard and root mean squared (RMS) deviations of $2 \times 10^{11} \mathrm{~m}^{-3}$. NPDM is climatological, i.e., the model describes the average behavior under quiet geomagnetic conditions. A preliminary comparison with the electron density NeQuick model (Hochegger et al. 2000; Radicella \& Leitinger 2001; Leitinger et al. 2005; Nava et al. 2008) reveals similar results for $\mathrm{NmF} 2$ with $\mathrm{RMS}$ deviations in the order of $2 \times 10^{11} \mathrm{~m}^{-3}$ and $5 \times 10^{11} \mathrm{~m}^{-3}$ for low and high solar activity conditions, respectively. NPDM can be very effective as a background model for near-real-time $\mathrm{NmF} 2$ reconstruction and prediction in operational services and radio systems (see examples of reconstructed $\mathrm{NmF} 2$ map at http://swaciweb.dlr.de/ daten-und-produkte/public/nmf2/).

\subsubsection{The Neustrelitz, Peak Height Model (NPHM)}

A global peak density height model, the NPHM, consisting of a set of nonlinear equations that explicitly describe the functional dependencies of hmF2 on local time, season, geographic/geomagnetic latitudes, and solar cycle variations, was recently developed (Hoque \& Jakowski 2012). The NPHM approach contains 13 unknown polynomial coefficients in addition to a few empirically fixed known parameters. The polynomial coefficients are derived by applying the model approach to a vast quantity of global $\mathrm{hmF} 2$ data derived from radio occultation and ionosonde measurements. Comparisons between NPHM and electron density NeQuick models for RMS estimates of their differences from observational data show that during high solar activity period the RMS deviations are about $13 \%$ and $18 \%$ for NPHM and NeQuick models, respectively. During low solar activity periods, the corresponding RMS estimates are $12 \%$ and $16 \%$, respectively. The great benefit of the new model is the ease of implementation and use. Due to limited number of coefficients, both the computation time and power will be significantly reduced in real-time ionosphere monitoring or modeling using the new model within any 3-D ionosphere model.

Within this framework, we could also report a recent investigation of Ünal et al. (2011) on the performance of International Reference Ionosphere (IRI)-based foF2 computations in forecasting basis. In particular, $1 \mathrm{~h}$ ahead forecasts of the foF2 provided by the Middle East Technical University Neural Network (METU-NN) model and IRI foF2 estimations were compared with observed values at middle-to-high latitudes (Slough and Uppsala). The two models are considered alternative to each other. Preliminary validation results verified that the two methods may be used in parallel employing METU-NN as the primary source for the foF 2 forecasting.

\subsection{GNSS predictions}

\subsubsection{Ionospheric monitoring based on GNSS data at ROB}

Since the end of 2011, the ionosphere above Europe is modeled in Near Real-Time (NRT) by ROB (http://gnss.be/ Atmospheric_Maps/ionospheric_maps.php). The models are represented in terms of Vertical TEC (VTEC) maps produced every $15 \mathrm{~min}$ on $0.5^{\circ} \times 0.5^{\circ}$ grid with a latency of 5-10 min after the last observation. The VTEC is estimated using Realtime GNSS data from the BKG NTRIP client (BNC, Söhne et al. 2010) of $\sim 125$ stations of the EUREF Permanent Network (EPN, Bruyninx et al. 2012).

To produce the VTEC maps, the slant TEC of each satellitereceiver pair are estimated and projected in VTEC at the Ionospheric Piercing Points (IPPs) using an ionospheric single thin layer shell approximation located at $450 \mathrm{~km}$ (Bergeot et al. 2011). The VTECs at the IPPs are then interpolated in a grid of $0.5^{\circ} \times 0.5^{\circ}$ using a spline interpolation.

For the processing, a geometry-free combination between each GPS satellite and receiver is performed using carrier phase leveled to the code. Products such as orbits and satellite Differential Code Biases (DCBs) are taken from the International GNSS Service (IGS, Dow et al. 2009) and from the Center 
VTEC DOY 069 11:45-12:00 UTC

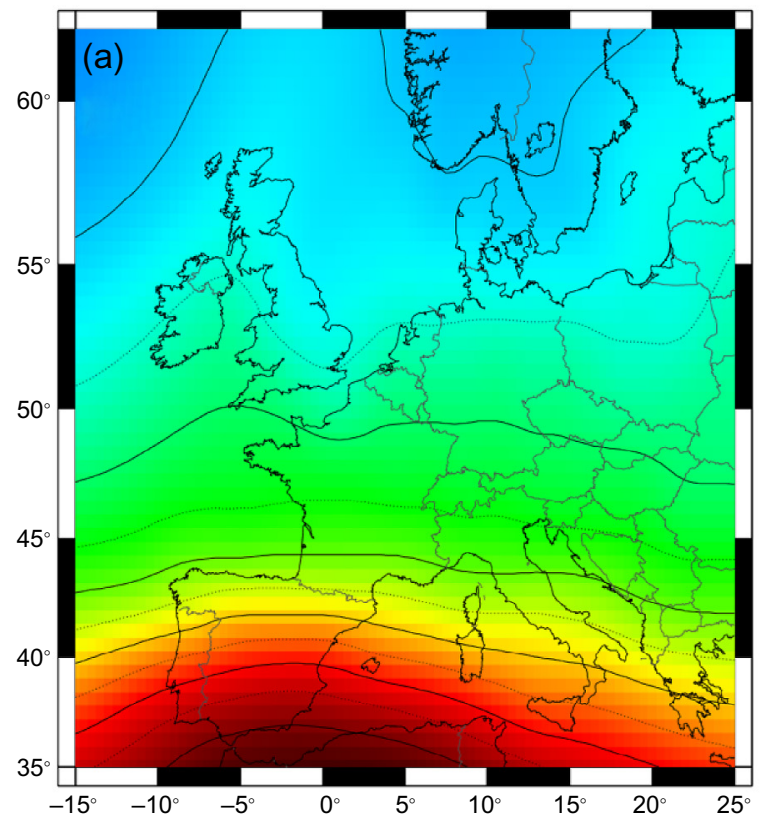

Difference VTEC $_{\text {current }}-\mathrm{VTEC}_{\text {median }}$

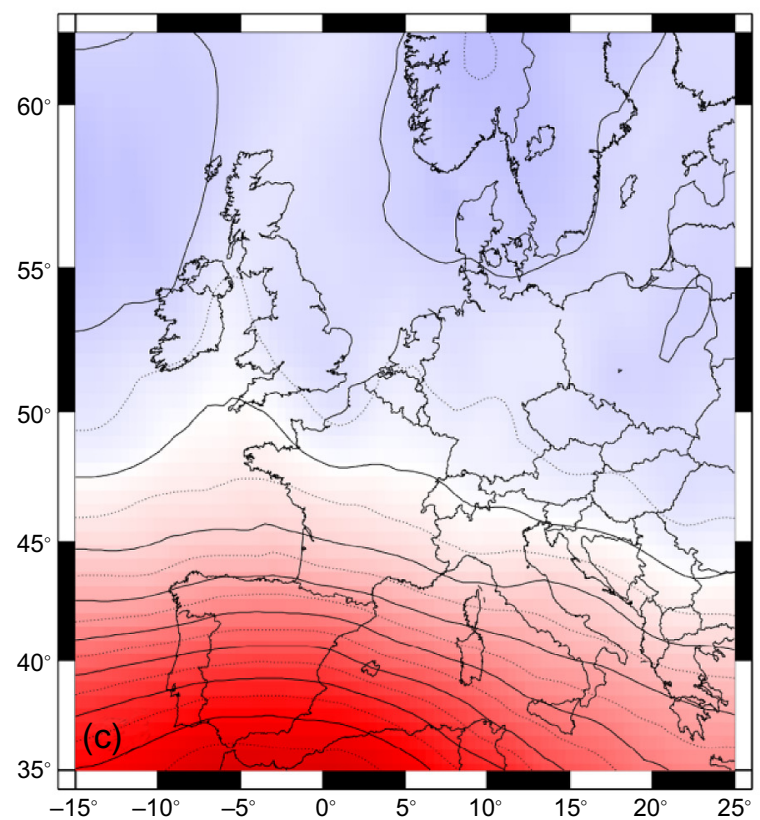

Median VTEC last 15 day 11:45-12:00 UTC

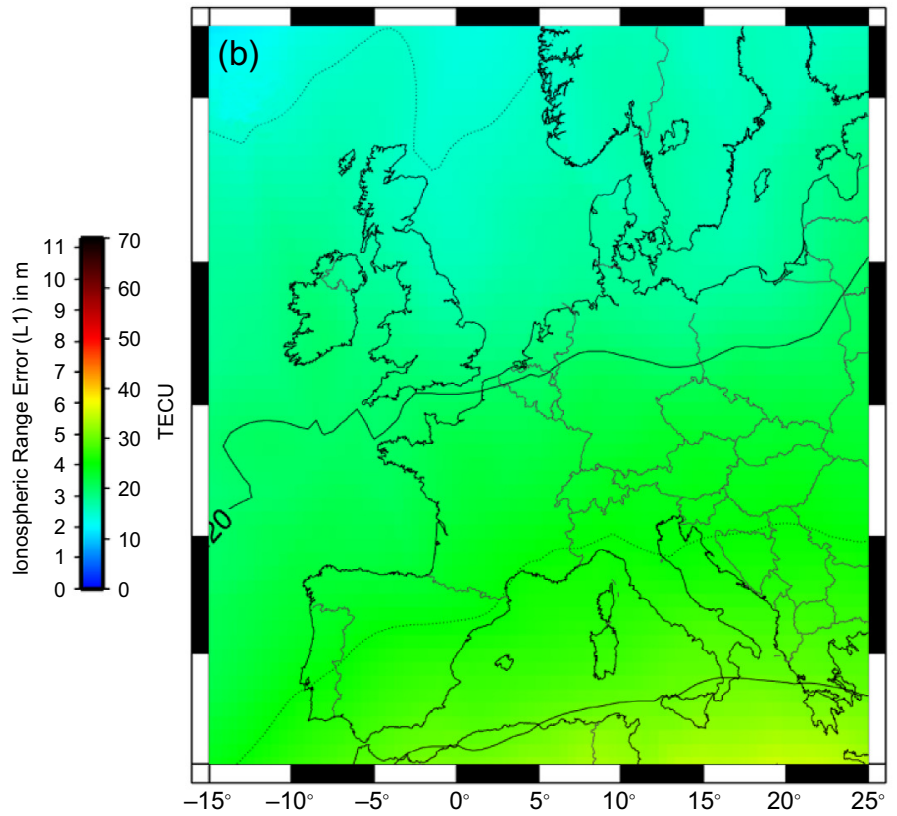

Histogram of the differences

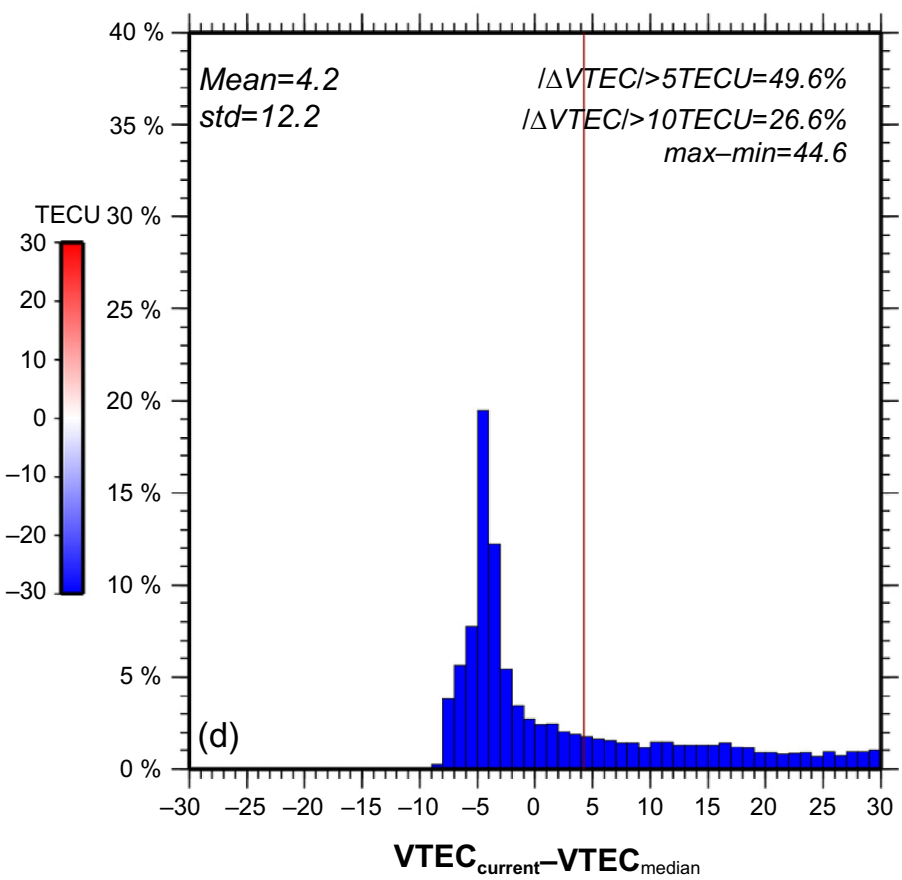

Fig. 9. VTEC maps over Europe during the 09/03/2012 (day of year 069) for the period 11:45-12:00 UTC. (a) Ionospheric models in NRT; (b) Previous 15 days median model; (c) Differences between (a) and (b); (d) histogram and statistics of the differences (http://gnss.be/ Atmospheric_Maps/static_ionospheric_maps.php). The color bars in the center represent the VTEC in TECU and the ionospheric range error (L1) in $\mathrm{m}$ (top), as well as the difference between the current and the median VTEC values in TECU (bottom).

for Orbit Determination in Europe (CODE, Schaer et al. 1998). The receiver DCBs are estimated using Rapid IONEX (IONosphere map EXchange format) of the IGS as a priori information.

The ionospheric product allows the detection in NRT of abnormal ionospheric activity with respect to the 15 previous days (see Fig. 9), which are generally due to high solar activity (e.g., solar flares, coronal mass ejection) which impact the
Earth's magnetosphere and ionosphere. The product is now available in two formats:

- An interactive product which allows the user to produce movies and to get quantification of the VTEC

- A statistical product with quantification of the differences between the NRT VTEC with respect to the previous 15 days. 


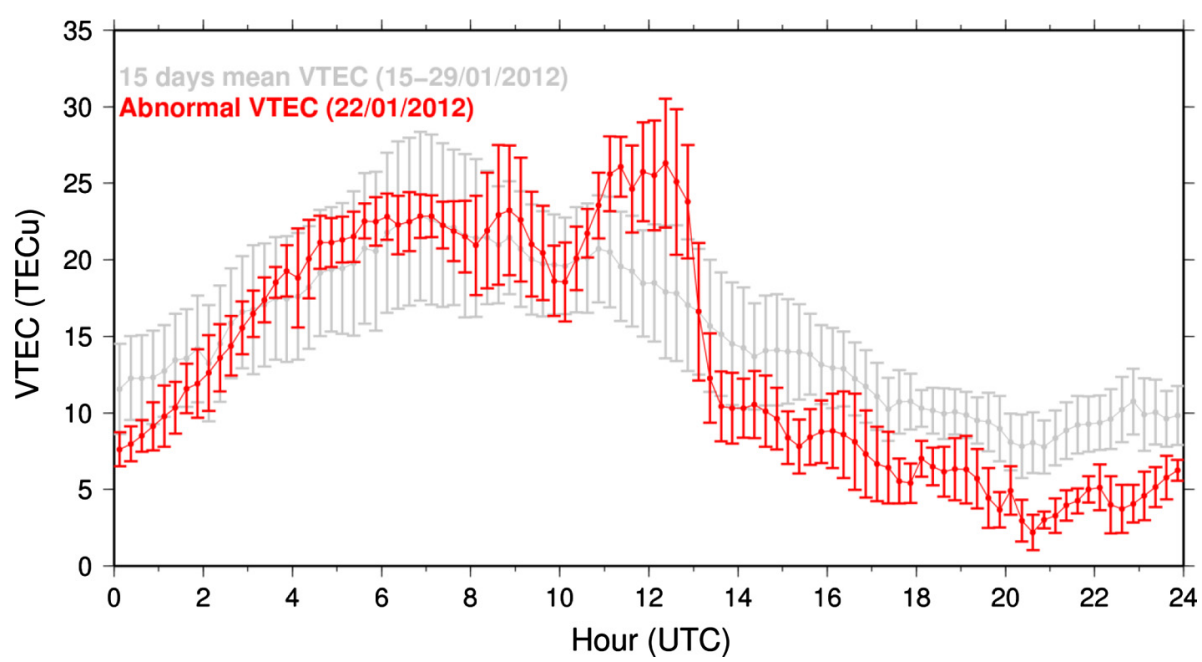

Fig. 10. VTEC above the PE station. Red: VTEC during the 22/01/2012 solar eruption impact; Gray: mean VTEC over 15 days around the $22 /$ 01/2012 (http://gnss.be/antarctica.php).

ROB was involved in the first season of scientific missions 2008-2009 at the Princess Elisabeth (PE) polar base (Antarctica, Utsteinen, S71 ${ }^{\circ} 56^{\prime} 48.1^{\prime \prime}$; E2320'46.8'). In 2009, during the inauguration of the base, the ROB installed a permanent high precision GPS station, called "ELIS" (ELISabeth, Belgium station). The continuous measurements of the position of this station will allow ROB to estimate the horizontal and vertical deformations of the Earth surface over time with a precision of one millimeter per year in the frame of the Geodesy for Ice in Antarctica (GIANT) project.

In parallel to the GIANT project and in the frame of the Solar-Terrestrial Centre of Excellence (STCE), we used the ELIS GPS data in order to monitor the ionosphere above the PE polar base. Figure 10 shows an example of an abnormal ionospheric activity due to a solar eruption which impacted the Earth magnetosphere on the $22 / 01 / 2012$. The increase of the VTEC occurs essentially around noon $(47 \%$ of increase of VTEC with respect to the normal ionospheric activity) before a general decrease after 14:00 UTC ( $\sim 40 \%$ of decrease of the VTEC with respect to the normal ionospheric activity). In the future a routine estimation of VTEC above the PE polar base will allow us to better understand the effect of solar eruption impact on Earth's upper atmosphere.

\subsubsection{TEC modeling activities at German Aerospace Center (DLR) in support of TEC monitoring activities in SWACI}

GNSS-based TEC monitoring is carried out in DLR Neustrelitz routinely since 1995 over the European area with a temporal resolution of 10 min (e.g., Jakowski 1996). The database is mainly provided by the European GPS ground station network of the International GNSS Service (Dow et al. 2009). Besides the European area also Northern Polar cap area $\left(\varphi>50^{\circ} \mathrm{N}\right)$ is monitored since 2002 (see http://www.kn.nz.dlr.de/daily/ tec-np/). Although the data coverage is extremely poor, also monitoring of the Southern Polar cap area $\left(\varphi>50^{\circ} \mathrm{S}\right)$ is carried out for DLR internal use (Jakowski et al. 2011a).

DLR is establishing an operational ionosphere data service via the SWACI project (http://swaciweb.dlr.de) since 2006. SWACI offers regional and global TEC nowcasting maps, corresponding model information, and hourly forecasts using ground- and space-based GNSS measurement techniques.
Based on currently applied procedures in the ionosphere data service SWACI, it was recently shown that TEC models can essentially help to calibrate TEC retrievals from GNSS data, to improve TEC mapping, and to estimate hourly TEC forecasts (Jakowski et al. 2011b). Consequently, a family of regional empirical TEC models, the Neustrelitz TEC Model (NTCM), has been developed in DLR which provides climatological information on TEC behavior: the NTCM-EU for Europe, and the NTCM-NP and NTCM-SP for North and South Pole areas, respectively (e.g., Jakowski 1996; Jakowski et al. 1998; Jakowski et al. 2011b). To ensure a high quality of the TEC maps also in case of only a few measurements or at greater distances from the measuring points, the measured data are combined with the empirical TEC model which has been developed specifically for the region in view.

Following the same principles of mathematical approach, also a global TEC model (NTCM-GL) has been recently developed (Jakowski et al. 2011a). This is an empirical model approach that allows determining global TEC, describing dependencies on local time, geographic/geomagnetic location, and solar irradiance and activity. The nonlinear approach needs only 12 coefficients and a few empirically fixed parameters for describing the broad spectrum of TEC variation at all levels of solar activity. The model approach is applied on high-quality global TEC data derived by the CODE at the University of Berne over more than half a solar cycle (1998-2007). The model fits to these input data with a negative bias of 0.3 TECU and a RMS deviation of 7.5 TECU. As other empirical models too, the NTCM-GL is climatological, i.e. the model describes the average behavior under quiet geomagnetic conditions. During severe space weather events the actual TEC data may deviate from the model values considerably by more than $100 \%$. A preliminary comparison with independent datasets as TOPEX/Poseidon altimeter data reveals similar results for NeQuick and NTCM-GL with RMS deviations in the order of 5 and 11 TECU for low- and high-solar activity conditions, respectively. The performance of the model may be further improved using an extended database which is expected to be available in the upcoming years. In particular, a higher time resolution of high-quality input data $(<2 \mathrm{~h})$ should improve the modeling results. The TEC database is expected to increase rapidly in the upcoming years enabling further improvement of the model coefficients and parameters. 
I. Tsagouri et al.: Progress in operational space weather models
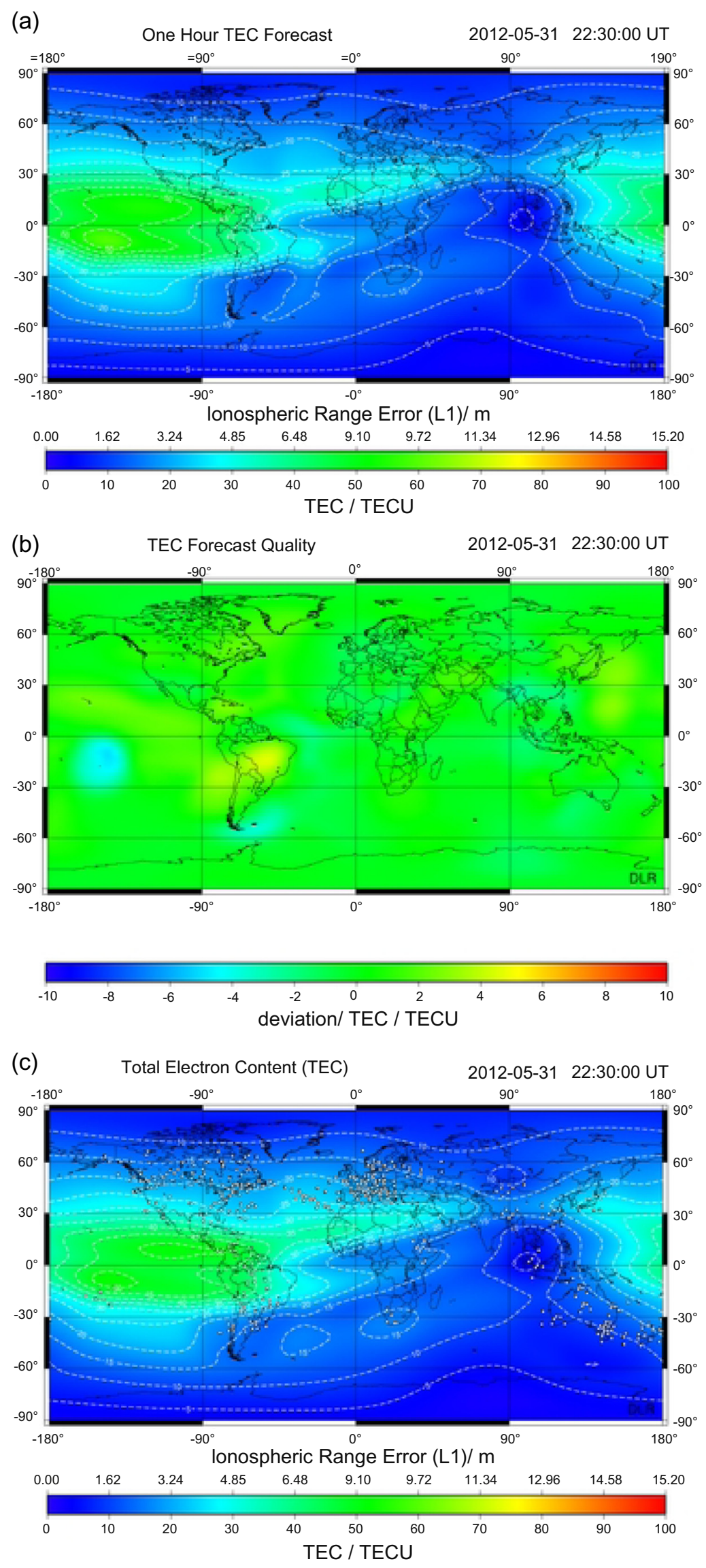

Fig. 11. (a) Routinely generated $1 \mathrm{~h}$ ahead TEC forecast on 31 May 2011 at 21:30 UT map in comparison with (b) the corresponding quality check of the hourly forecast made at 20:30 UT for 21:30 UT. Shown are the absolute TEC deviations of the forecast from the actual TEC map. Via SWACI both plots are provided simultaneously in conjunction with the actual TEC map at 21:30 UT (bottom) (http://swaciweb.dlr.de). 
Although nowcast information of ionospheric propagation errors helps already in GNSS application practice, forecast of errors and their development are of particular interest for GNSS customers. Since there is always a time delay between time of measurements and service provision, the derived propagation errors do not exactly correspond to actual propagation conditions. Thus, to give an example, SWACI provides TEC maps with an update rate of $5 \mathrm{~min}$. Considering the delay due to computation time and data management, the provided information is delayed by about $8 \mathrm{~min}$ at user level. To overcome this operational gap, corresponding forecast tools can be applied. Doing so, the user can work with an estimated real-time value. If applications require some warning or planning time to be well prepared when ionospheric perturbations are approaching, the forecast must exceed the aforementioned time interval. Since currently no reliable forecasts of ionospheric behavior during perturbations are available, much work must still be done. In this direction, a simple model-assisted forecasting algorithm was recently introduced (Jakowski et al. 2011b), which may help to provide some preliminary results and to learn about ionospheric forecast problems. Figure 11 provides a $1 \mathrm{~h}$ sample forecast as an example. The TEC map-related forecast algorithm takes benefit from actual trends of the TEC behavior at each grid point. During perturbations, characterized by large TEC fluctuations or ionisation fronts, this approach may seriously fail. So the trend information is merged with the current background model which provides a stable climatologically TEC behavior. In average such a forecast will be better than applying the trend or model approach alone.

\subsection{Predicting space weather effects in the Earth's atmosphere}

\subsubsection{Now- and Short-term Forecasting of the Chemical Composition of the Middle Atmosphere}

At PMOD/WRC a climate-chemistry-ionosphere model (CICM) SOCOL ${ }^{\mathrm{i}}$ has been developed, which is based on a general circulation model and includes complete representation of the chemistry of neutral and ionized species in the atmosphere from the ground up to the mesopause. The CICM SOCOL ${ }^{\mathrm{i}}$ (Egorova et al. 2011) in nowcasting mode is now running using near real-time online SSI data provided by LPC2E (Lab. de Physique et Chimie de l'Environnement et de l'Espace) (http://lpc2e.cnrs-orleans.fr/ soteria/). Initially we supposed to use online SSI data based on the PROBA2/LYRA and the PICARD/PREMOS radiometers. Because of the rapid degradation of some of the channels of the former, and the late launch of PICARD, whose data have not been officially released yet, a backup solution was adopted. At the moment, nowcast of the SSI data is based on solar continuum images, and solar magnetograms from SDO/HMI, which are segmented and then fed into an analog neural network model that has been trained using daily solar spectra from SORCE/SIM, SORCE/SOLSTICE and SORCE/XPS. The SSI data is delivered every $3 \mathrm{~h}$ for wavelengths from 1-40 and 115-360 $\mathrm{nm}$ to nowcast the chemical composition of the middle atmosphere.

The service of the middle atmosphere parameters nowcasting is fully operational. We provide online nowcast of the middle atmosphere every $2 \mathrm{~h}$ for $\mathrm{O}_{3}, \mathrm{NO}, \mathrm{NO}_{2}, \mathrm{OH}, \mathrm{H}_{2} \mathrm{O}$ volume mixing ratio, electron and total positive ion density, temperature, air density, and geopotential height. A short-term forecasting up to 1 day is also available. The output from the model consists of the 3-D atmospheric quantities for the current time step and nearest future (up to 1 day). A progressive archive of the past calculations is also publicly available online at http://projects.pmodwrc.ch/lyra/nowcast_data and can be used for educational purposes. The forecast and archive data are stored in NetCDF format.

\subsubsection{COsmic Ray Ionization Model for Ionosphere and Atmosphere (CORIMIA)}

The program CORIMIA is developed for calculation of the electron production rate profiles due to cosmic rays (CR) using ionization losses (Bohr-Bethe-Bloch function) approximation in six characteristic energy intervals, including the charge decrease interval for electron capturing (Velinov et al. 2012a, 2012b). In this way the accuracy of the obtained results is improved in comparison with fewer characteristic energy interval approximations.

The program CORIMIA is applied for the case of penetration of galactic $\mathrm{CR}$, anomalous $\mathrm{CR}$, and solar $\mathrm{CR}$ in middle atmosphere and lower ionosphere $(30-120 \mathrm{~km})$. The results are shown using profile evaluation for differential spectra of the full CR composition: protons p, Helium (alpha particles), Light $\mathrm{L}(3 \leq Z \leq 5)$, Medium $\mathrm{M}(6 \leq Z \leq 9)$, Heavy $\mathrm{H}$ $(Z \geq 10)$, and Very Heavy VH $(Z \geq 20)$ nuclei ( $Z$ is the charge of the penetrating CR nucleus). The profiles are computed for solar minimum (when the atmospheric ionization is maximum) and show good agreement with experimental data.

The effect of sporadic solar CR and energetic particle events is investigated also. It can be very strong locally in the polar cap regions, affecting the electrical and physical-chemical properties of the lower, middle, and upper atmosphere and especially the global atmospheric electrical circuit (Tonev \& Velinov 2011; Velinov et al. 2013).

Analytical expressions and contributions in percent of some characteristic energy intervals are provided. These contributions reflect the physical structure of the ionization process. A submodel for investigation of atmospheric cut-offs formation is created (Velinov \& Mateev 2008a, 2008b; Velinov et al. 2009, 2011a, 2011b).

\subsubsection{COsmic Radiation Influence on Atmospheric Electric Circuit (CORIAEC)}

A program code CORIAEC is developed for physics-based 3D numerical simulation model designed to evaluate the steadystate response of the global atmospheric electrical circuit (AEC) to variations of the solar wind (SW) parameters and of the galactic cosmic rays modulated by SW. On one hand, the solar wind influences AEC through the polar cap ionospheric convection potential changes: the ionospheric transpolar potential difference of 40-140 kV (governed by SW) of horizontal dimension of $\sim 3000 \mathrm{~km}$, in combination with the field-aligned currents, leads to penetration of electric fields in AEC domain at high and polar latitudes. According to different authors (Makarova et al. 1998; Corney et al. 2003; Tinsley et al. 2007) these superimposed electric fields penetrate as far as down to the Earth's surface and modify the potential gradient. On the other hand, the conductivity in the upper troposphere and strato/mesosphere is created mainly by galactic CR of energies $<10^{11} \mathrm{eV}$. The modifications of galactic CR by SW cause short- (e.g., by Forbush effects) and long-term (during 11-year 
solar cycle) variations of the AEC conductivity parameters, which lead to respective changes of AEC characteristics, such as the air-earth current and potential gradient. The model CORIAEC serves to study AEC characteristics and their variations at high and polar latitudes due to influence of SW, and due to changes of atmospheric conductivity related to modulation of galactic CR flux by SW (Velinov \& Tonev 2008; Tonev \& Velinov 2010, 2011).

\subsection{Ground-based predictions}

\subsubsection{Conversion of post-analysis GIC software to real-time analyzers}

The EU/FP7 Project EURISGIC (No. 260330) started in March 2011 and has the following objectives:

- To produce the first European-wide real-time prototype forecast service of GIC in power systems based on in-situ solar wind observations and comprehensive simulations of the Earth's magnetosphere.

- To derive the first map of the statistical risk of large GIC throughout Europe by utilizing geomagnetic recordings. Worst-case GIC scenarios based on historical data will also be investigated.

EURISGIC will exploit the knowledge and advanced modeling methods developed in Europe and North America (especially in the Solar Shield project of the NASA Applied Sciences program, see Pulkkinen et al. 2010). Close communication throughout the project with a stakeholder advisory group will help in directing the research and outreach appropriately. The results of this study will help in the future design of more robust and secure protection against GIC in power transmission grids in Europe, which are anticipated to become increasingly interconnected and geographically wider.

During the first project year, the following progress has been reached aiming at improving operational GIC models (Viljanen et al. 2012): previously existing methods and software have been successfully updated to be capable for Europeanscale GIC modeling in the spherical geometry. This contains compilation of a prototype model of the European high-voltage power grid, and collection of ground conductivity models for the calculation of the geoelectric field. For developing a prototype forecast service using real-time solar wind data, the previously existing magnetosphere-ionosphere simulation code (Janhunen 1996) has been made faster by parallelization. Simultaneously, an empirical model by Wintoft et al. (2005) relating solar wind measurements to the time derivative of ground magnetic field has been further developed.

As a preparation for the forecast server, we have tested the updated GIC software using real-time IMAGE magnetometer data from 13 stations in North Europe. From the measured magnetic field, we first derive equivalent ionospheric currents. We can then interpolate the ground magnetic field at any point, calculate the geoelectric field and finally GIC in power grids or pipelines. An example of a magnetic storm on 15 March 2012 is shown in Figures 12 and 13. There was a very rapid increase in electrojet amplitudes around 17 UT. This caused a large time derivative of the magnetic field and a prominent increase of GIC. Later analysis showed that the maximum measured GIC was about $33 \mathrm{~A}$ (1-min value), so the real-time calculation provided a very realistic output.

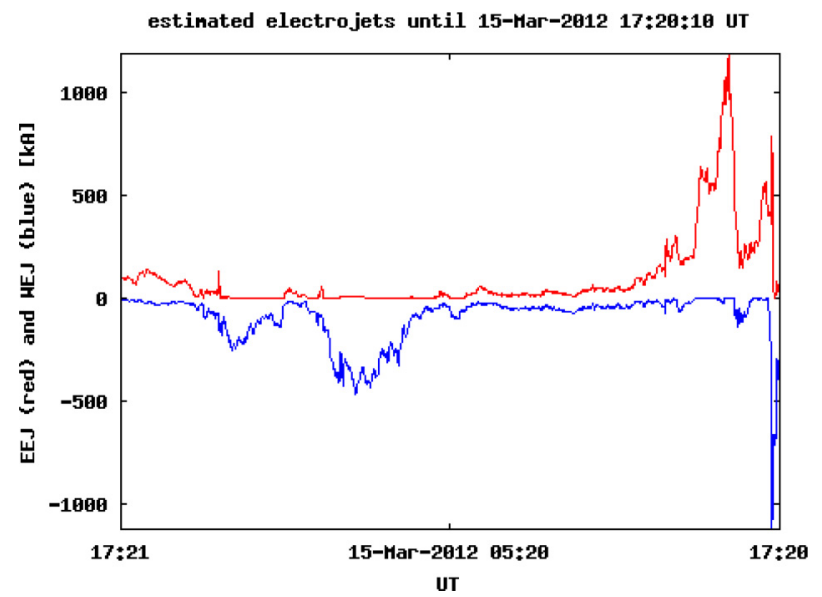

Fig. 12. Estimated eastward (red) and westward (blue) electrojets across Finland in 14 March 17:21 UT to 15 March 2012 17:20 UT.

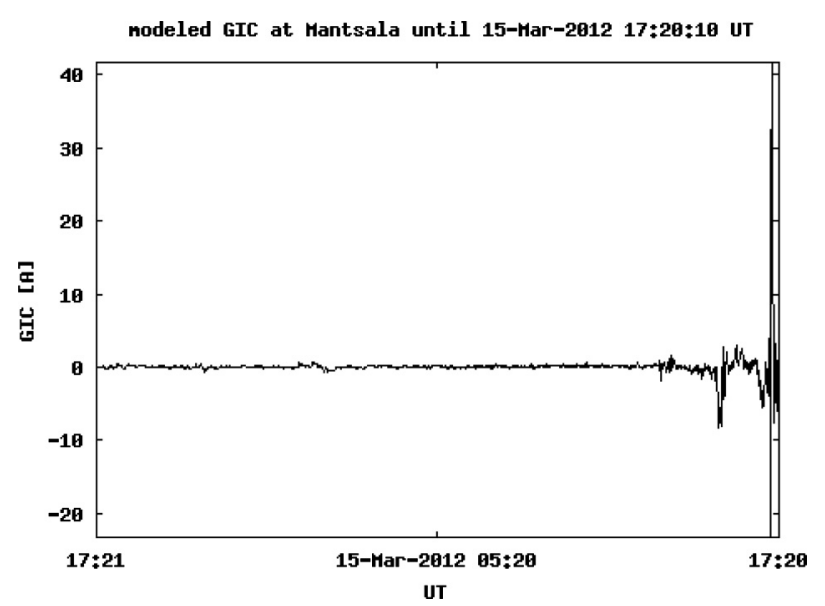

Fig. 13. Modeled GIC (1-min values) along the Finnish natural gas pipeline at the Mantsala compressor station. Positive value refers to an eastward current.

\section{Overview of the improved nowcasting and forecasting capabilities}

In this section, we attempt to provide a comprehensive summary of the improved nowcasting and forecasting modeling capabilities discussed in Section 3. This part is focused on the models available in operational or pre-operational mode. More precisely, the COST ES0803 recommendations presented here include models that run effectively in operational systems, but also those that are currently in the process of being transitioned to operations, as well as models that could be considered as candidates for transition to operations by the space weather community today. The results are presented in Table 1, following the models' classification of Section 3. For each case (introduced in the first column), we start by considering the observed input data including the drivers (second column of Table 1) and the output parameters and/or services (third column of Table 1). Key sources of validation results are provided in the fourth column, while the prediction mode is given in the last column.

Most of the models presented in Table 1 run operationally to provide space weather products and services to the user communities through systems operated either by national research institutes and/or by internationally coordinated initiatives, as for example ESA/SWENET, DIAS, and SWACI in Europe as 
Table 1. Summarized overview of models reviewed within SG1.3 of COST ES0803.

\begin{tabular}{|c|c|c|c|c|}
\hline $\begin{array}{l}\text { Model name and } \\
\text { references }\end{array}$ & Observed input & $\begin{array}{l}\text { Output parameters/ } \\
\text { products and services }\end{array}$ & $\begin{array}{l}\text { Validation results } \\
\text { (key references) }\end{array}$ & Prediction mode \\
\hline \multicolumn{5}{|c|}{ Solar weather predictions } \\
\hline $\begin{array}{l}\text { ASAP } \\
\text { Colak \& Qahwaji } \\
2009\end{array}$ & $\begin{array}{l}\text { SOHO/MDI } \\
\text { (SDO/HMI) } \\
\text { Continuum and } \\
\text { magnetogram } \\
\text { images }\end{array}$ & $\begin{array}{l}\text { Real-time prediction } \\
\text { for the occurrence of } \\
\text { flares }\end{array}$ & $\begin{array}{l}\text { Verbeeck et al. } 2013 \\
\text { Colak \& Qahwaji } 2011\end{array}$ & Forecast \\
\hline SPoCA-suite & $\begin{array}{l}\text { SDO-AIA } \\
\text { images }\end{array}$ & $\begin{array}{l}\text { Detect, extract, and } \\
\text { track active regions } \\
\text { and coronal holes on } \\
\text { EUV images }\end{array}$ & & Nowcast \\
\hline \multirow[t]{2}{*}{$\begin{array}{l}\text { UMASEP } \\
\text { Núñez } 2011\end{array}$} & $\begin{array}{l}\text { Flare and near- } \\
\text { Earth space } \\
\text { environment } \\
\text { data (Soft X- } \\
\text { ray differential } \\
\text { and integral } \\
\text { proton fluxes) }\end{array}$ & $\begin{array}{l}\text { SEP warnings } \\
\text { i) time interval within } \\
\text { which the integral } \\
\text { proton flux is expected } \\
\text { to meet or surpass the } \\
\text { SWPC SEP threshold } \\
\text { of } \mathrm{J}(E>10 \mathrm{MeV})=10 \\
\text { pr } \mathrm{cm}^{-2} \mathrm{sr}^{-1} \mathrm{~s}^{-1} \text {, }\end{array}$ & Núñez 2011 & Forecast \\
\hline & & $\begin{array}{l}\text { ii) intensity of the first } \\
\text { hours of SEP events. }\end{array}$ & & \\
\hline
\end{tabular}

\section{Geomagnetic predictions}

$\begin{array}{lll}\text { UAH-SWS } & \text { IMF-Bz } & \text { i) Warning of severe } \\ \text { Saiz et al. 2008 } & \text { component } & \begin{array}{l}\text { geomagnetic } \\ \text { disturbances }\end{array} \\ \text { Aguado et al. } 2010 & \text { Dst index } & \end{array}$

ii) Estimate of the time remaining for the magnetosphere to recover quiet time conditions.

$\begin{array}{lllll}\begin{array}{l}\text { HDK } \\ \text { Kutiev et al. 2009a }\end{array} & \begin{array}{l}\text { Ground-based } \\ \text { magnetic data }\end{array} & K \text { index } & \text { Kutiev et al. 2009a } & \text { Nowcast and Forecast } \\ & \text { Solar wind data } & & \end{array}$

\section{Satellite environment predictions}

\section{$\mathrm{TaD}$}

Kutiev et al. 2010

Kutiev et al. 2012
F10.7 index

$K p$ index

Digisonde-

derived

bottomside

electron density

profiles
Reconstructed electron density profiles up to geosynchronous heights over Digisonde locations
Belehaki et al. 2010

Belehaki et al. 2012
Forecast

Nowcast

\begin{tabular}{|c|c|c|c|c|}
\hline \multicolumn{5}{|c|}{ Communications predictions } \\
\hline $\begin{array}{l}\text { SIRMUP } \\
\text { Zolesi et al. } 2004 \\
\text { Tsagouri et al. } 2010\end{array}$ & $\begin{array}{l}R_{12} \\
\text { Real-time foF } 2 \\
\text { observations }\end{array}$ & $\begin{array}{l}\text { Regional nowcasting } \\
\text { foF2 maps }\end{array}$ & $\begin{array}{l}\text { Zolesi et al. } 2004 \\
\text { Tsagouri et al. } 2005 \\
\text { Tsagouri et al. } 2010\end{array}$ & Nowcast \\
\hline
\end{tabular}


Table 1. (Continued)

\begin{tabular}{|c|c|c|c|c|}
\hline $\begin{array}{l}\text { Model name and } \\
\text { references }\end{array}$ & Observed input & $\begin{array}{l}\text { Output parameters/ } \\
\text { products and services }\end{array}$ & $\begin{array}{l}\text { Validation results } \\
\text { (key references) }\end{array}$ & Prediction mode \\
\hline $\begin{array}{l}\text { SWIF } \\
\text { Tsagouri et al. } 2009\end{array}$ & $\begin{array}{l}\text { IMF } \\
\text { observations at } \\
\text { L1 point (IMF- } \\
\text { Btotal, IMF-Bz) } \\
\text { foF2 } \\
\text { observations } \\
\text { (real time and } \\
\text { past) }\end{array}$ & $\begin{array}{l}\text { foF2 for single } \\
\text { locations } \\
\text { Regional foF2 } \\
\text { forecasting maps } \\
\text { (forecasts } 1-24 \mathrm{~h} \\
\text { ahead) } \\
\text { Warnings for } \\
\text { upcoming ionospheric } \\
\text { storm disturbances }\end{array}$ & $\begin{array}{l}\text { Tsagouri et al. } 2009 \\
\text { Tsagouri } 2011\end{array}$ & Forecast \\
\hline $\begin{array}{l}\text { GCAM } \\
\text { Muhtarov et al. } 2002 \\
\text { Tsagouri } 2011\end{array}$ & $\begin{array}{l}\text { Ap index } \\
\text { (predictions and } \\
\text { actual records) } \\
\text { foF2 } \\
\text { observations } \\
\text { (real time and } \\
\text { past) }\end{array}$ & $\begin{array}{l}\text { foF } 2 \text { for single } \\
\text { locations } \\
\text { Regional foF } 2 \\
\text { forecasting maps } \\
\text { (forecasts } 1-24 \mathrm{~h} \\
\text { ahead) }\end{array}$ & $\begin{array}{l}\text { Tsagouri et al. } 2009 \\
\text { Tsagouri } 2011\end{array}$ & Forecast \\
\hline $\begin{array}{l}\text { IFERM } \\
\text { Pietrella } 2012\end{array}$ & $\begin{array}{l}a p(\tau) \\
\text { foF2 } \\
\text { (measurements } \\
\text { and reference } \\
\text { estimates) }\end{array}$ & $\begin{array}{l}\text { Regional foF } 2 \text { maps } \\
\text { over Europe (forecasts } \\
1-3 \mathrm{~h} \text { ahead) }\end{array}$ & Pietrella 2012 & Forecast \\
\hline $\begin{array}{l}\text { NPDM } \\
\text { Hoque \& Jakowski } 2011\end{array}$ & $\begin{array}{l}\text { F10.7 } \\
\text { (current or } \\
\text { predicted values } \\
\text { depending on } \\
\text { the prediction } \\
\text { mode) }\end{array}$ & $\begin{array}{l}\mathrm{NmF} 2 \text { at selected time } \\
\text { and location }\end{array}$ & $\begin{array}{l}\text { Hoque \& Jakowski } \\
2011\end{array}$ & Nowcast and forecast \\
\hline NPHM & $\begin{array}{l}\text { F10.7 } \\
\text { (current or } \\
\text { predicted values } \\
\text { depending on } \\
\text { the prediction } \\
\text { mode) }\end{array}$ & $\begin{array}{l}\mathrm{hmF} 2 \text { at selected time } \\
\text { and location }\end{array}$ & $\begin{array}{l}\text { Hoque \& Jakowski } \\
2012\end{array}$ & Nowcast and forecast \\
\hline
\end{tabular}

\section{GNSS predictions}

VTEC- model-assisted monitoring at ROB

Bergeot et al. 2011

\section{NTCM-GL}

Model-assisted TEC Monitoring (5 min update)

\section{NRT GNSS \\ data \\ European area}

F10.7

(current or predicted values depending on the prediction mode)

NRT GNSS NRT TEC maps
data

Global

European area

VTEC maps maps and location
Nowcast

VTEC disturbances

TEC at selected time

Jakowski et al. 2011a, 2011b
Jakowski 1996
Jakowski et al. 1998
Gulyaeva \& Jakowski
1999
Belehaki et al. 2003
Feltens et al. 2011

Nowcast

.


Table 1. (Continued)

\begin{tabular}{|c|c|c|c|c|}
\hline $\begin{array}{l}\text { Model name and } \\
\text { references }\end{array}$ & Observed input & $\begin{array}{l}\text { Output parameters/ } \\
\text { products and services }\end{array}$ & $\begin{array}{l}\text { Validation results } \\
\text { (key references) }\end{array}$ & Prediction mode \\
\hline $\begin{array}{l}\text { Model-assisted } \\
\text { TECForecast (1 h) }\end{array}$ & $\begin{array}{l}\text { NRT GNSS } \\
\text { data } \\
\text { Global } \\
\text { European area }\end{array}$ & $\begin{array}{l}\text { NRT TEC map } 1 \mathrm{~h} \\
\text { forecast }\end{array}$ & $\begin{array}{l}\text { Immediate control at the } \\
\text { end of the forecast } \\
\text { interval } \\
\text { Jakowski et al. } 2011 \mathrm{~b}\end{array}$ & Forecast \\
\hline \multicolumn{5}{|c|}{ Space weather effects in the Earth's atmosphere } \\
\hline $\begin{array}{l}\text { CICM SOCOL }^{\mathrm{i}} \\
\text { Egorova et al. } 2011\end{array}$ & NRT SSI data & $\begin{array}{l}\mathrm{O}_{3}, \mathrm{NO}, \mathrm{NO}_{2}, \mathrm{OH}, \\
\mathrm{H}_{2} \mathrm{O} \text { volume mixing } \\
\text { ratio, } \\
\text { electron and total } \\
\text { positive ion density, } \\
\text { temperature, air } \\
\text { density and } \\
\text { geopotential height. }\end{array}$ & & Nowcast and Forecast \\
\hline $\begin{array}{l}\text { CORIMIA } \\
\text { Velinov et al. 2012a, } \\
\text { 2012b } \\
\text { Velinov et al. } 2013\end{array}$ & $\begin{array}{l}\text { Charge } Z \text { of the } \\
\text { galactic cosmic } \\
\text { ray particle } \\
\text { Galactic cosmic } \\
\text { ray spectrum } \\
\text { parameters }\end{array}$ & $\begin{array}{l}\text { Atmospheric cut-offs } \\
\text { for the corresponding } \\
\text { altitude; } \\
\text { Electron production } \\
\text { rate for the cusp region } \\
\text { and corresponding } \\
\text { altitude; } \\
\text { Electron production } \\
\text { rate for the } \\
\text { corresponding altitude } \\
\text { and geomagnetic } \\
\text { latitude. }\end{array}$ & $\begin{array}{l}\text { Velinov et al. 2012a } \\
\text { Velinov et al. } 2012 \mathrm{~b} \\
\text { Velinov et al. } 2013\end{array}$ & Nowcast \\
\hline $\begin{array}{l}\text { CORIAEC } \\
\text { Tonev \& Velinov } 2011\end{array}$ & $\begin{array}{l}\text { Solar wind plasma } \\
\text { density, velocity, } \\
\text { IMF: By, Bz, }\end{array}$ & $\begin{array}{l}\text { Distributions of } \\
\text { electric field, } \\
\text { potential, and } \\
\text { current density, } \\
\text { Altitudes: } 0-100 \mathrm{~km} \text {, } \\
\text { Latitudes: above } 45^{\circ} \text {. }\end{array}$ & Tonev \& Velinov 2011 & Nowcast \\
\hline \multicolumn{5}{|l|}{ Ground-based predictions } \\
\hline Real time GIC analyzers & $\begin{array}{l}\text { Real-time solar } \\
\text { wind data } \\
\text { Ground magnetic } \\
\text { field records }\end{array}$ & GIC & Viljanen et al. 2006 & Nowcast \\
\hline
\end{tabular}

well as iSWA and HEK in the US. Results that are currently available through the operational use of these models for exploitation by end-users include: solar weather and geomagnetic activity predictions, ionospheric and trans-ionospheric propagation predictions, and atmospheric chemical composition predictions. The availability of products and services related to satellite environment and GIC predictions is foreseen in the near future through the implementation of the relevant models, which is envisaged by European research teams.

The final products (e.g., nowcasts, forecasts, and alerts/ warnings) are made available in several graphical (e.g., maps, plots) and numerical data file formats. In practice, there is also a variety of means of access to the results, as a response to different users' requirements. Web access is the most widely used one, but ftp and email deliveries of the data are often possible. In addition, in several cases the services are supported by tutorial and outreach material, as well as software applications in an effort of the European community to promote and facilitate the use of the available resources. Interactive communication between service providers and users is usually established through training activities, workshops, and conferences. Among others, a key role holds the annual European Space Weather Week (ESWW), a top venue for space weather stakeholders. The last years, the ESWWs are jointly organized by the Belgian STCE, ESA, the Space Weather Working Team, and the COST ES0803 communities to offer a variety of communication links 
(e.g., scientific sessions, splinter and business meetings, tutorials, debates, and fairs) between space weather scientists, service developers, and providers and users.

\section{Conclusions}

Considerable progress in operational space weather modeling has been recorded in the last decade in Europe. Currently, the European community is in possession of a significant number of unique space weather models that are adapted to operational requirements to drive the development of valuable space weather products and services. This was achieved through the implementation of several national and European coordinated activities among which the two successive European COST actions (COST 724 and COST ES0803) hold a key role.

Empirical modeling and data-driven techniques are still the main drivers of the development of operational models and tools. Therefore, the availability of routine observations from both the space and the ground, as well as the routine availability of indices and proxies, remain essential requirements for the development, validation/verification, maintenance, and improvement of space weather operations. This in turn implies both maintenance of the existing observing platforms and establishment of new ones, as means of understanding and as input to space weather models. Going further on the latter, it is important to realize that the reliability and the accuracy of space weather models depend strongly on the quality of the data ingested. Based on this, one may argue that the continued improvement and development of space weather observing capabilities could result in better coverage, timeliness, and accuracy of space weather products and services. This requirement was also noted in the 2010 US NSWP Strategic Plan (available at http://www.nswp.gov/).

A strong requirement for the successful transition from research to operational models is the systematic validation of the models' performance. In addition, the validation tests should be based on well-established metrics so that the improvements in nowcasting and forecasting capabilities can be promptly monitored and assessed. The European activity in this matter has lagged behind the work that is performed within the US, as for example the pioneering work that the CCMC performs on the validation of US models (http:// ccmc.gsfc.nasa.gov/). COST ES0803 spent appreciable effort to put the systematic validation of the European space weather models into discussion and to mobilize the European community toward this direction. There is clear evidence indicating some progress in this field based on individual efforts, but there is still much to be done and the validation of space weather models remains an open and urgent issue for the European community. Significant support to this effort is expected not only from the expansion of the observed datasets in the future, but also from the improved access to space weather data that will be achieved through new European investments made within EU/FP7. These include recent activities, such as the SEPServer project (http://www.sepserver.eu/sepserver/) that was designed to facilitate the access to high-quality SEP data and related electromagnetic observations for the study and prediction of SEP events, but also the European e-Infrastructures that are currently deployed or under deployment. Such examples include SOTERIA that worked on a higher level of accessibility for the observational data and for the models in solarspace and geophysics domains (http://soteria-space.eu/), HELIO that will provide a comprehensive integrated information system in heliophysics domain (http://www.heliovo.eu/), and ESPAS that aims at providing integrated access to near-Earth space data (http://www.espas-fp7.eu/).

Finally, one should always keep in mind that accurate space weather predictions require a high level of understanding of the underlying physics. Therefore, the continued support to space weather research remains always an essential requirement for further improvements in space weather operational modeling.

Acknowledgements. This review is based on the activities of Sub Group 1.3 "Improvement of operational models" of the European COST Action ES0803. Special acknowledgements are due to Jurgen Watermann for many useful discussions and active support throughout this work.

\section{Appendix}

\section{List of acronyms and abbreviations}

\begin{tabular}{|c|c|}
\hline $\mathrm{ACE}$ & Advanced Composition Explorer \\
\hline $\mathrm{AEC}$ & Atmospheric Electrical Circuit \\
\hline AFWA & Air Force Weather Agency \\
\hline AIA & Atmospheric Imaging Assembly (SDO) \\
\hline ASAP & Automated Solar Activity Prediction system \\
\hline ATMOP & $\begin{array}{l}\text { Advanced Thermosphere Modelling for Orbit } \\
\text { Prediction project }\end{array}$ \\
\hline AWT & Average Warning Time \\
\hline BKG & $\begin{array}{l}\text { Bundesamtes für Kartographie und Geodäsie } \\
\text { (Federal Agency for Cartography and Geod- } \\
\text { esy - Germany) }\end{array}$ \\
\hline CCMC & $\begin{array}{l}\text { Community Coordinated Modeling Center } \\
\text { (US) }\end{array}$ \\
\hline CHAMP & $\begin{array}{l}\text { Challenging Mini-Satellite Payload for Geo- } \\
\text { scientific Research and Applications program }\end{array}$ \\
\hline CICM & Climate-Chemistry-Ionosphere Model \\
\hline $\mathrm{CME}$ & Coronal Mass Ejection \\
\hline CODE & Center for Orbit Determination in Europe \\
\hline COMESEP & $\begin{array}{l}\text { Coronal Mass Ejections and Solar Energetic } \\
\text { Particles project }\end{array}$ \\
\hline CORIAEC & $\begin{array}{l}\text { COsmic Radiation Influence on the Atmo- } \\
\text { spheric Electrical Circuit }\end{array}$ \\
\hline CORIMIA & $\begin{array}{l}\text { COsmic Ray Ionization Model for Iono- } \\
\text { sphere and Atmosphere }\end{array}$ \\
\hline COST & European Cooperation in Science and Technology \\
\hline $\mathrm{CR}$ & Cosmic Rays \\
\hline $\mathrm{DCBs}$ & Differential Code Biases \\
\hline DIAS & European Digital Upper Atmosphere Server \\
\hline DLR & German Aerospace Center \\
\hline DTM & Drag Temperature Model \\
\hline EIT & $\begin{array}{l}\text { Extreme Ultraviolet Imaging Telescope } \\
(\mathrm{SOHO})\end{array}$ \\
\hline EPCARD & $\begin{array}{l}\text { European Program Package for the Calcula- } \\
\text { tion of Aviation Route Doses }\end{array}$ \\
\hline EPN & EUREF Permanent Network \\
\hline ESA & European Space Agency \\
\hline ESP & $\begin{array}{l}\text { Extreme Ultraviolet Spectro-Photometer } \\
(\text { EVE/SDO) }\end{array}$ \\
\hline ESPAS & $\begin{array}{l}\text { Near-Earth space data infrastructure for e-sci- } \\
\text { ence }\end{array}$ \\
\hline ESWW & European Space Weather Week \\
\hline EUREF & EUropean REference Frame \\
\hline
\end{tabular}




\begin{tabular}{|c|c|c|c|}
\hline EURISGIC & $\begin{array}{l}\text { European Risk from Geomagnetically In- } \\
\text { duced Currents project }\end{array}$ & $\begin{array}{l}\text { NPDM } \\
\text { NRT }\end{array}$ & $\begin{array}{l}\text { Neustrelitz Peak Density Model } \\
\text { Near Real-Time }\end{array}$ \\
\hline EUV & Extreme Ultraviolet & NSWP & National Space Weather Program (US) \\
\hline EVE & $\begin{array}{l}\text { Extreme ultraviolet Variability Experiment } \\
\text { (SDO) }\end{array}$ & $\begin{array}{l}\text { NTCM } \\
\text { NTCM-EU }\end{array}$ & $\begin{array}{l}\text { Neustrelitz TEC Model } \\
\text { NTCM for Europe }\end{array}$ \\
\hline FAR & False Alarm Rate & NTCM-GL & NTCM GLobal \\
\hline GCAM & $\begin{array}{l}\text { Geomagnetically Correlated Autoregression } \\
\text { Model }\end{array}$ & $\begin{array}{l}\text { NTCM-NP } \\
\text { NTCM-SP }\end{array}$ & $\begin{array}{l}\text { NTCM for North Pole } \\
\text { NTCM for South Pole }\end{array}$ \\
\hline GIANT & Geodesy for Ice in Antarctica project & NTRIP & Network Transport of RTCM data over IP \\
\hline GIC & Geomagnetically Induced Currents & $\mathrm{PE}$ & Princess Elisabeth station (Antarctica) \\
\hline GIFINT & $\begin{array}{l}\text { Geomagnetic Indices Forecasting and Iono- } \\
\text { spheric Nowcasting Tools }\end{array}$ & PMOD/WRC & $\begin{array}{l}\text { Physikalisch-Meteorologisches Observatori- } \\
\text { um Davos and World Radiation Center }\end{array}$ \\
\hline $\begin{array}{l}\text { GNSS } \\
\text { GOES }\end{array}$ & $\begin{array}{l}\text { Global Navigation Satellite System } \\
\text { Geostationary Operational Environmental } \\
\text { Satellites }\end{array}$ & $\begin{array}{l}\text { PREMOS } \\
\text { POD }\end{array}$ & $\begin{array}{l}\text { PREcision MOnitor Sensor } \\
\text { Probability of Detection }\end{array}$ \\
\hline GPS & Global Positioning System & PROBA & PRoject for OnBoard Autonomy \\
\hline GSM & $\begin{array}{l}\text { Geocentric Solar Magnetospheric coordinate } \\
\text { System }\end{array}$ & $\begin{array}{l}\text { REFM } \\
\text { RMS }\end{array}$ & $\begin{array}{l}\text { Relativistic Electron Forecast Model } \\
\text { Root Mean Square }\end{array}$ \\
\hline HDK & Hybrid Dourbes $K$ model & ROB & Royal Observatory of Belgium \\
\hline HEK & Heliophysics Events Knowledgebase system & SDAs & Service Development Activities \\
\hline HELIO & Heliophysics Integrated Observatory & SDO & Solar Dynamics Observatory \\
\hline $\mathrm{HF}$ & High Frequency range of the radio spectrum & SG & Sub Group \\
\hline HMI & Helioseismic and Magnetic Imager (SDO) & SEP & Solar Energetic Particle \\
\hline IFERM & $\begin{array}{l}\text { Ionospheric Forecasting Empirical Regional } \\
\text { Model }\end{array}$ & SEPEM & $\begin{array}{l}\text { Solar Energetic Particle Environment Model- } \\
\text { ling project }\end{array}$ \\
\hline IFELM & $\begin{array}{l}\text { Ionospheric Forecasting Empirical Local } \\
\text { Models }\end{array}$ & $\begin{array}{l}\text { SIDC } \\
\text { SIM }\end{array}$ & $\begin{array}{l}\text { Solar Influences Data Analysis Centre (ROB) } \\
\text { Spectral Irradiance Monitor (SORCE) }\end{array}$ \\
\hline IGS & International GNSS Service & SIRM & Simplified Ionospheric Regional Model \\
\hline IMAGE & $\begin{array}{l}\text { International Monitor for Auroral Geomag- } \\
\text { netic Effects }\end{array}$ & SIRMUP & $\begin{array}{l}\text { Real-time updating of the Simplified Iono- } \\
\text { spheric Regional Model }\end{array}$ \\
\hline IMAGE/RPI & $\begin{array}{l}\text { Imager for Magnetopause-to-Aurora Global } \\
\text { Exploration/Radio Plasma Imager }\end{array}$ & $\begin{array}{l}\text { SMART } \\
\text { SOHO }\end{array}$ & $\begin{array}{l}\text { Solar Monitor Active Region Tracker } \\
\text { Solar and Heliospheric Observatory }\end{array}$ \\
\hline IMF & Interplanetary Magnetic Field & SOLPENCO & SOLar Particle ENgineering Code \\
\hline $\begin{array}{l}\text { IONEX } \\
\text { IPPs }\end{array}$ & $\begin{array}{l}\text { IONosphere maps EXchange format } \\
\text { Ionospheric Piercing Points }\end{array}$ & SOLSTICE & $\begin{array}{l}\text { SOlar Stellar Irradiance Comparison Experi- } \\
\text { ment (SORCE) }\end{array}$ \\
\hline IRI & International Reference Ionosphere & SORCE & Solar Radiation and Climate Experiment \\
\hline ISR & Incoherent Scatter Radar & SOTERIA & Solar-Terrestrial Investigations and Archives \\
\hline ISS & International Space Station & SPENVIS & Space Environment Information System \\
\hline iSWA & $\begin{array}{l}\text { Integrated Space Weather Analysis system } \\
\text { (NASA/US) }\end{array}$ & $\begin{array}{l}\text { SPoCA } \\
\text { SSA }\end{array}$ & $\begin{array}{l}\text { Spatial Possibilistic Clustering Algorithm } \\
\text { SWE Space Situational Awareness - Space }\end{array}$ \\
\hline LEO & Low Earth Orbit & & Weather segment $(\mathrm{ESA})$ \\
\hline LMSAL & $\begin{array}{l}\text { Lockheed Martin Solar and Astrophysics } \\
\text { Laboratory (US) }\end{array}$ & $\begin{array}{l}\text { SSI } \\
\text { STCE }\end{array}$ & $\begin{array}{l}\text { Spectral Solar Irradiance } \\
\text { Solar-Terrestrial Centre of Excellence }\end{array}$ \\
\hline LPC2E & $\begin{array}{l}\text { Laboratoire de Physique et Chimie de l'Envi- } \\
\text { ronnement et de l'Espace }\end{array}$ & $\begin{array}{l}\text { STIM } \\
\text { SW }\end{array}$ & $\begin{array}{l}\text { Empirical Storm-Time Ionospheric Model } \\
\text { Solar Wind }\end{array}$ \\
\hline $\begin{array}{l}\text { LYRA } \\
\text { MAK }\end{array}$ & $\begin{array}{l}\text { LYman alpha Radiometer (PROBA2) } \\
\text { Muhtarov-Andonov-Kutiev model }\end{array}$ & SWACI & $\begin{array}{l}\text { Space Weather Application Center - Iono- } \\
\text { sphere }\end{array}$ \\
\hline MDI & Michelson Doppler Imager (SOHO) & SWENET & Space Weather European Network (ESA) \\
\hline METU-NN & $\begin{array}{l}\text { The Middle East Technical University Neu- } \\
\text { ral Network model }\end{array}$ & SWIF & $\begin{array}{l}\text { Solar Wind driven autoregression model for } \\
\text { Ionospheric short-term Forecast }\end{array}$ \\
\hline MFs & Magnetic Features & SWPS & Space Weather Prediction Center (NOAA/ \\
\hline MULASSIS & $\begin{array}{l}\text { Multi-Layered Shielding Simulation Soft- } \\
\text { ware }\end{array}$ & SWS & $\begin{array}{l}\text { US) } \\
\text { Space Weather Service (UAH) }\end{array}$ \\
\hline NASA & $\begin{array}{l}\text { National Aeronautics and Space Administra- } \\
\text { tion (US) }\end{array}$ & $\mathrm{TaD}$ & $\begin{array}{l}\text { Topside Sounder Model Profiler - assisted } \\
\text { Digisonde }\end{array}$ \\
\hline NetCDF & Network Common Data Form & TEC & Total Electron Content \\
\hline NOAA & $\begin{array}{l}\text { National Oceanic and Atmospheric Adminis- } \\
\text { tration (US) }\end{array}$ & $\begin{array}{l}\text { TSAR } \\
\text { TSMP }\end{array}$ & $\begin{array}{l}\text { Time Series AutoRegressive model } \\
\text { Topside Sounder Model Profiler }\end{array}$ \\
\hline NPHM & Neustrelitz Peak Height Model & UAH & Universidad de Alcalá de Henares \\
\hline
\end{tabular}


I. Tsagouri et al.: Progress in operational space weather models

ULF Ultra-low frequency

US United States

VTEC Vertical Total Electron Content

WSA Wang-Sheeley-Arge model

XPS XUV Photometer System (SORCE)

\section{References}

Aguado, J., C. Cid, E. Saiz, and Y. Cerrato, Hyperbolic decay of the Dst index during the recovery phase of intense geomagnetic storms, J. Geophys. Res., 115, A07220,

DOI: 10.1029/2009JA014658, 2010.

Ahmed, O.W., R. Qahwaji, T. Colak, P.A. Higgins, P.T. Gallagher, and D. Shaun Bloomfield, Solar flare prediction using advanced feature extraction, machine learning, and feature selection, Sol. Phys., 283 (1), 157-175,

DOI: $10.1007 / \mathrm{s} 11207-011-9896-1,2013$.

Andonov, B., P. Muhtarov and I. Kutiev, Analogue model relating kp index to solar wind parameter, J. Atmos. Sol. Terr. Phys., 66 (11), 927, 2004

Aran, A., B. Sanahuja, and D. Lario, SOLPENCO: A solar particle engineering code, Adv. Space Res., 37 (6), 1240, 2006.

Araujo-Pradere, E.A., T.J. Fuller-Rowell, and M.V. Codrescu, STORM: An empirical storm time ionospheric correction model: 1. Model description, Radio Sci., 37 (5), 1070,

DOI: 10.1029/2001RS002467, 2002.

Araujo-Pradere, E.A., Transitioning space weather models into operations: The basic building blocks, Space Weather, 7, S10006, DOI: 10.1029/2009SW000524, 2009.

Arge, C.N., J.G. Luhmann, D. Odstrcil, C.J. Schrijver, and Y. Li, Stream structure and coronal sources of the solar wind during the May 12th, 1997 CME, J. Atmos. Sol. Terr. Phys., 66 (15-16), 1295-1309, 2004.

Balch, C.C., Updated verification of the Space Weather Prediction Center's solar energetic particle prediction model, Space Weather, 6, S01001, DOI: 10.1029/2007SW000337, 2008.

Barra, V., V. Delouille, M. Kretzschmar, and J.F. Hochedez, Fast and robust segmentation of solar EUV images: algorithm and results for solar cycle 23, Astron. Astrophys., 505 (1), 361-371, 2009.

Belehaki, A., and J. Lilensten, COST724: Conclusions and Way Ahead, Edited by Jean, Lilensten, Anna Belehaki, Mauro Messerotti, Rami Vainio, and Jurgen Watermann, COST 724 Final Report: Developing the Scientific Basis for Monitoring, Modelling, and Predicting Space Weather, COST Office, Luxembourg, ISBN 978-92-898-0044-0, 2008.

Belehaki, A., N. Jakowski, and B. Reinisch, Comparison of Ionospheric ionization measurements over Athens using ground ionosonde and GPS derived TEC values, Radio Sci., 38 (6), DOI: 10.1029/2003RS002868, 2003.

Belehaki, A., I. Kutiev, N. Jakowski, and S. Stankov, Comparison of the topside ionosphere scale height determined by topside sounders model and bottomside Digisonde profiles, Adv. Space Res., 37 (5), 963-966, 2006a.

Belehaki, A., Lj. Cander, B. Zolesi, J. Bremer, C. Juren, I. Stanislawska, D. Dialetis, and M. Hatzopoulos, Monitoring and forecasting the ionosphere over Europe: The DIAS project, Space Weather, 4, S12002, DOI: 10.1029/2006SW000270, 2006b.

Belehaki, A., L. Cander, B. Zolesi, J. Bremer, C. Juren, I. Stanislawska, D. Dialetis, and M. Hatzopoulos, Ionospheric specification and forecasting based on observations from European ionosondes participating in DIAS project, Acta Geophys., 55 (3), 398-409, 2007.

Belehaki, A., I. Kutiev, B. Reinisch, N. Jakowski, P. Marinov, I. Galkin, C. Mayer, I. Tsagouri, and T. Herekakis, Verification of the TSMP-assisted Digisonde (TaD) topside profiling technique,
Acta Geophys., 58 (3), 432-452,

DOI: $10.2478 / \mathrm{s} 11600-009-0052-3,2010$.

Belehaki, A., I. Stanislawska, and J. Lilensten, An overview of ionosphere - thermosphere models available for space weather purposes, Space Sci. Rev., 147, 271-313, DOI: $10.1007 / \mathrm{s} 11214-009-9510-0,2009 \mathrm{a}$.

Belehaki, A., J. Watermann, J. Lilensten, A. Glover, M. Hapgood, M. Messerotti, R. van der Linden, and H. Lundstedt, Renewed support dawns in Europe: An action to develop space weather products and services, Space Weather, 7, S03001, 2009b.

Belehaki, A., I. Tsagouri, and P. Marinov, An improved model for operational specification of the electron density structure up to GNSS orbits assisted by Digisonde data, Edited by J.M., Goodman (Editor-in-Chief), Proceedings of the $13^{\text {th }}$ International Ionospheric Effects Symposium 2011, pp. 204-211, Alexandria, US, May 17-19, 2011.

Belehaki, A., I. Tsagouri, I. Kutiev, P. Marinov, and S. Fidanova, Upgrades to the topside sounders model assisted by Digisonde (TaD) and its validation at the topside ionosphere, J. Space Weather Space Clim., 2, A20, 2012.

Bergeot, N., C. Bruyninx, P. Defraigne, S. Pireaux, J. Legrand, E. Pottiaux, and Q. Baire, Impact of the Halloween 2003 ionospheric storm on kinematic GPS positioning in Europe, GPS Solut., 15 (2), 171, DOI: 10.1007/s10291-010-0181-9, 2011.

Bourdarie, S., D. Boscher, T. Beutier, J.A. Sauvaud, M. Blanc, and R. Friedel, A Physic Based Model of the Radiation Belt Flux at the Day Timescale, Edited by W., Burke, and T.-D. Guyenne, Proceedings of the Symposium on Environment Modelling for Space-Based Applications, Eur. Space Agency Spec. Publ., ESA SP-392, pp. 159-163, 1996.

Bruinsma, S.L., N. Sánchez-Ortiz, E. Olmedo, and N. Guijarro, Evaluation of the DTM-2009 thermosphere model for benchmarking purposes, J. Space Weather Space Clim., 2, A04, DOI: 10.1051/swsc/2012005, 2012.

Bruyninx, C., H. Habrich, W. Söhne, A. Kenyeres, G. Stangl, and C. Völksen, Enhancement of the EUREF Permanent Network Services and Products, Geodesy for Planet Earth, IAG Symposia Series, 136, 27-35, DOI: 10.1007/978-3-642-20338-1_4, 2012.

Cid, C., E. Saiz, and Y. Cerrato, Comment on "Interplanetary conditions leading to superintense geomagnetic storms (Dst $\leq 250 \mathrm{nT}$ ) during solar cycle 23", Geophys. Res. Lett., 35, L21107, DOI: 10.1029/2008GL034731, 2008.

Colak, T., and R. Qahwaji, ASAP: hybrid computer platform using machine learning and solar imaging for automated prediction of significant solar flares, Space Weather, 7, S06001, DOI: 10.1029/2008SW000401, 2009.

Colak, T., and R. Qahwaji, Prediction of extreme ultraviolet variability experiment (EVE)/extreme ultraviolet spectro-photometer (ESP) irradiance from solar dynamics observatory (SDO)/ atmospheric imaging assembly (AIA) images using fuzzy image processing and machine learning, Sol. Phys., 283 (1), 143-156, DOI: 10.1007/s11207-011-9880-9, 2013.

Colak, T., R. Qahwaji, S. Ipson, and H.H. Ugail, Representation of solar features in 3D for creating visual solar catalogues, $A d v$. Space Res., Special Issue on Space Weather Advances, 47 (12), 2092-2104, 2011.

Corney, R.C., G.B. Burns, K. Michael, A.V. Frank-Kamenetsky, O.A. Troshichev, E.A. Bering, V.O. Papitashvili, A.M. Breed, and M.L. Duldig, The influence of polar-cap convection on the geoelectric field at Vostok, Antarctica, J. Atmos. Sol. Terr. Phys., 65, 345-354, 2003.

Degtyarev, V.I., I.P. Kharchenko, A.S. Potapov, B. Tsegmed, and S.E. Chudnenko, Qualitative estimation of magnetic storm efficiency in producing relativistic electron flux in the Earth's outer radiation belt using geomagnetic pulsations data, Adv. Space Res., 43 (5), 829-836, DOI: 10.1016/j.asr.2008.07.004, 2009.

Degtyarev, V.I., I.P. Kharchenko, A.S. Potapov, B. Tsegmed, and S.E. Chudnenko, The relation between geomagnetic pulsations and an increase in the fluxes of geosynchronous relativistic 
electrons during geomagnetic storms, Geomag. Aeron., 50 (7), 885-893, 2010.

Delouille, V., B. Mampaey, C. Verbeeck, and R. de Visscher, The SPoCA-suite: a software for extraction and tracking of active regions and coronal holes on EUV images, Arxive-prints, 1208.1483, 2012.

Dow, J.M., R.E. Neilan, and C. Rizos, The international GNSS service in a changing landscape of Global Navigation Satellite Systems, $J$. Geod., 83, 191-198, DOI: 10.1007/s00190-008-0300-3, 2009.

Egorova, T., E. Rozanov, Y. Ozolin, A. Shapiro, M. Calisto, T. Peter, and W. Schmutz, The atmospheric effects of October 2003 solar proton event simulated with the chemistry-climate model SOCOL using complete and parameterized ion chemistry, J. Atmos. Sol. Terr. Phys., 1073 (2-3), 356-365, DOI: 10.1016/j.jastp.2010.01.009, 2011.

Feltens, J., M. Angling, N. Jackson-Booth, N. Jakowski, M. Hoque, M. Hernández-Pajares, A. Aragón-Àngel, R. Orús, and R. Zandbergen, Comparative testing of four ionospheric models driven with GPS measurements, Radio Sci., 46, RS0D12, DOI: 10.1029/2010RS004584, 2011.

Fuller-Rowell, T., E.A. Araujo-Pradere, C. Minter, M. Codrescu, P. Spencer, D. Robertson, and A.R. Jacobson, US-TEC: a new data assimilation product from the Space Environment Center characterizing the ionospheric total electron content using real-time GPS data, Radio Sci., 41, RS6003, DOI: 10.1029/2005RS003393, 2006 .

Gulyaeva, T.L., and N. Jakowski, Validation of consistency of GPS NTCM2 and SMI-96 derived maps of total electron content through the ionosphere and plasmasphere, Edited by R., Hanbaba, and B.A. de la Morena, Proceedings of the 3rd COST251 Workshop, September, 1998, pp. 109-118, 1999.

Higgins, P.A., P.T. Gallagher, R.T.J. McAteer, and D.S. Bloomfield, Solar magnetic feature detection and tracking for space weather monitoring, Adv. Space Res., Space weather advances, 47 (12), 2105-2117, 2011.

Hochegger, G., B. Nava, S.M. Radicella, and R. Leitinger, A family of ionospheric models for different uses, Phys. Chem. Earth, 25 (4), 307-310, DOI: 10.1016/S1464-1917(00)00022-2, 2000.

Hoque, M.M., and N. Jakowski, A new global empirical NmF2 model for operational use in radio systems, Radio Sci., 46, RS6015, DOI: 10.1029/2011RS004807, 2011.

Hoque, M.M., and N. Jakowski, A new global model for the ionospheric F2 peak height for radio wave propagation, Ann. Geophys., 30, 787-809, DOI: 10.5194/angeo-30-797-2012, 2012.

Houminer, Z., J.A. Bennett, and P.L. Dyson, Real-time ionospheric model updatingJournal of Electrical and Electronics Engineering, Australia, IE Aust. \& IREE Aust., 13 (2), 99-104, 1993.

Jacchia, L.G., and J. Slowey, Accurate drag determinations for eight artificial satellites: atmospheric densities and temperatures, Smithsonian Contrib. Astrophys., 8, 1, 1963.

Jakowski, N., TEC Monitoring by Using Satellite Positioning Systems, Edited by H., Kohl, R. Ruester, and K. Schlegel, Modern Ionospheric Science, Eur. Geophys. Soc., KatlenburgLindau, Germany, pp. 371-390, 1996

Jakowski, N., E. Sardón, and S. Schlueter, GPS-based TEC observations in comparison with IRI95 and the European TEC model NTCM2, Adv. Space Res., 22, 803-806, DOI: 10.1016/S0273-1177(98)00101-X, 1998.

Jakowski, N., M.M. Hoque, and C. Mayer, A new global TEC model for estimating transionospheric radio wave propagation errors, $J$ Geod., 85, 965-974, DOI: 10.1007/s00190-011-0455-1, 2011a.

Jakowski, N., C. Mayer, M.M. Hoque, and V. Wilken, Total electron content models and their use in ionosphere monitoring, Radio Sci., 46, RS0D18, DOI: 10.1029/2010RS004620, 2011 b.

Janhunen, P., GUMICS-3: a global ionosphere-magnetosphere coupling simulation with high ionospheric resolution, Proceedings of Environmental Modelling for Space-Based Applications, 18-20 Sep 1996, Eur. Space Agency Spec. Publ., ESA SP-392, 1996.
Koutroumbas, K., I. Tsagouri, and A. Belehaki, Time series autoregression technique implemented on-line in DIAS system for ionospheric forecast over Europe, Ann. Geophys., 26 (2), 371386, 2008.

Kutiev, I., and P. Marinov, Topside sounder model of scale height and transition height characteristics of the ionosphere, Adv. Space Res., 39, 759-766, DOI: 10.1016/j.asr.2006.06.013, 2007.

Kutiev, I., P. Marinov, and S. Watanabe, Model of topside ionosphere scale height based on topside sounder data, $A d v$. Space Res., 37 (5), 943-950, 2006.

Kutiev, I., P. Muhtarov, B. Andonov, and R. Warnant, Hybrid model for nowcasting and forecasting the $\mathrm{K}$ index, J. Atmos. Sol. Terr. Phys., 71, 589-596, DOI: 10.1016/j.jastp.2009.01.005, 2009a.

Kutiev, I., P. Marinov, A. Belehaki, B. Reinisch, and N. Jakowski, Reconstruction of topside density profile by using the Topside Sounder Model Profiler and Digisonde data, Adv. Space Res., 43, 1683-1687, 2009b.

Kutiev, I., P. Marinov, A. Belehaki, N. Jakowski, B. Reinisch, C. Mayer, and I. Tsagouri, Plasmaspheric electron density reconstruction based on the Topside Sounder Model Profiler, Acta Geophys., 58 (3), 420-431, DOI: 10.2478/s11600-009-0051-4, 2010.

Kutiev, I., P. Marinov, S. Fidanova, A. Belehaki, and I. Tsagouri, Adjustments of the $\mathrm{TaD}$ electron density reconstruction model with GNSS-TEC parameters for operational application purposes, J. Space Weather Space Clim., 2, A21, 2012.

Kutiev, I., I. Tsagouri, L. Perrone, D. Pancheva, P. Mukhtarov, et al., Solar activity impact on the Earth's upper atmosphere, J. Space Weather Space Clim., 3, A06, 2013.

Lathuillere, C., M. Menvielle, J. Lilensten, T. Amari, and S.M. Radicella, From the Sun's atmosphere to the Earth's atmosphere: an overview of scientific models available for space weather developments, Ann. Geophys., 20, 1081-1104, 2002.

Lei, F., P.R. Truscott, C.S. Dyer, B. Quaghebeur, D. Heynderickx, P. Nieminen, H. Evans, and E. Daly, MULASSIS: a Geant4-based multilayered shielding simulation tool, IEEE T. Nucl. Sci., 49, 6, 2002.

Leitinger, R., M.L. Zhang, and S.M. Radicella, An improved bottomside for the ionospheric electron density model NeQuick, Ann. Geophys., 48 (3), 525-534, 2005.

Lilensten, J., T. Clark, and A. Belehaki, Europe's first space weather think tank, Space Weather, 2, S04001, 2004.

Makarova, L.N., A.V. Shirochkov, and K.V. Koptjaeva, The Earth's magnetopause as an element of the global electric circuit, IEEE T. Nucl. Sci., 38 (3), 156-159, (in Russian), 1998.

Mares, V., T. Maczka, G. Leuthold, and W. Ruehm, Air crew dosimetry with a new version of EPCARD, Radiation Protection Dosimetry, 136 (4), 262-266, 2009.

Martin, A.R., Spacecraft/Plasma Interactions and Electromagnetic Effects in LEO and Polar Orbits, Final Report for ESA/ESTEC Contract No.7989/88/NL/PB(SC), Vol. 3, 1991.

Messenger, C.G., and M.S. Ash, Single Event Phenomena, Chapman \& Hall, New York, 1997

Messerotti, M., F. Zuccarello, S.L. Guglielmino, V. Bothmer, J. Lilensten, G. Noci, M. Storini, and H. Lundstedt, Solar weather event modelling and prediction, Space Sci. Rev., 147, 121-185, DOI: 10.1007/s11214-009-9574-x, 2009.

Mikhailov, A.V., A. Belehaki, L. Perrone, B. Zolesi, and I. Tsagouri, Retrieval of thermospheric parameters from routine ionospheric observations: assessment of method's performance at midlatitudes daytime hours, J. Space Weather Space Clim., 2, A03, 2012.

Mikhailov, A.V., A. Belehaki, L. Perrone, B. Zolesi, and I. Tsagouri, Retrieval of thermospheric parameters from routinely observed F2-layer $\mathrm{Ne}(\mathrm{h})$ profiles at the geomagnetic equator, J. Space Weather Space Clim., 3, A15, 2013.

Muhtarov, P., I. Kutiev, and L. Cander, Geomagnetically correlated autoregression model for short-term prediction of ionopsheric parameters, Inverse Prob., 18, 49-65, 2002. 
Nava, B., P. Coisson, and S.M. Radicella, A new version of the NeQuick ionosphere electron density model, J. Atmos. Sol. Terr. Phys., 76, 1856-1862, 2008.

Núñez, M., Predicting Solar Energetic Proton Events (E > $10 \mathrm{MeV})$, Space Weather, 9, S07003, DOI: 10.1029/2010SW000640, 2011.

Pietrella, M., A short-term ionospheric forecasting empirical regional model (IFERM) to predict the critical frequency of the F2 layer during moderate, disturbed, and very disturbed geomagnetic conditions over the European area, Ann. Geophys., 30, 343-355, DOI: 10.5194/angeo-30-343-2012, 2012.

Pizzo, V., G. Millward, A. Parsons, D. Biesecker, S. Hill, and D. Odstrcil, Wang-Sheeley-Arge-Enlil cone model transitions to operations, Space Weather, 9, S03004, DOI: 10.1029/2011SW000663, 2011.

Potapov, A.S., and T.N. Polyushkina, Experimental evidence for direct penetration of ULF waves from the solar wind and their possible effect on acceleration of radiation belt electrons, Geomag. Aeron., 50 (8), 28-34, 2010.

Pulkkinen, A., M. Hesse, L. Van der Zel, B. Damsky, F. Policelli, D. Fugate, W. Jacobs, and E. Creamer, Solar shield: forecasting and mitigating space weather effects on high-voltage power transmission systems, Nat. Hazards, 53, 333-345, DOI: $10.1007 / \mathrm{s} 11069-009-9432-x, 2010$.

Radicella, S.M., and R. Leitinger, The evolution of the DGR approach to model electron density profiles, Adv. Space Res., 27, 35-40, DOI: 10.1016/S0273-1177(00)00138-1, 2001.

Reitz, G., and T. Berger, The Matroshka facility - dose determination during an EVA, Radiat. Prot. Dosim., 120, 442-445, 2006.

Saiz, E., C. Cid, and Y. Cerrato, Forecasting intense geomagnetic activity using interplanetary magnetic field data, Ann. Geophys., 26, 3989-3998, 2008.

Schaer, S., W. Gurtner, and J. Feltens, IONEX: the IONosphere Map EXchange Format version 1, Proceedings of the 1998 IGS analysis centres workshop, ESOC, Darmstadt, Germany, 9-11 Feb, pp. 233-247, 1998.

Stanislawska, I., A. Belehaki, N. Jakowski, B. Zolesi, T. Gulyaeva, Lj.R. Cander, B.W. Reinisch, M. Pezzopane, I. Tsagouri, L. Tomasik, and I. Galkin, COST 296 scientific results designed for operational use, Ann. Geophys., 54 (3/4), 423-435, 2009.

Tinsley, B.A., G.B. Burns, and L. Zhou, The role of the global electric circuit in solar and internal forcing of clouds and climate, Adv. Space Res., 40, 1126-1139, 2007.

Tobiska, W.K., Space Weather Management, AIAA-2009-1494, 2009.

Tonev, P., and P.I.Y. Velinov, Conditions for creation of streamers in lower ionosphere above lightning discharges with continuing currents, C.R. Acad. Bulg. Sci., 63 (12), 1787-1794, 2010.

Tonev, P.T., and P.I.Y. Velinov, Model study of the influence of solar wind parameters on electric currents and fields in middle atmosphere at high latitudes, C.R. Acad. Bulg. Sci., 64 (12), 1733-1742, 2011.

Tsagouri, I., Evaluation of the performance of DIAS ionospheric forecasting models, J. Space Weather Space Clim., 1, A02, DOI: $10.1051 /$ swsc/2011110003, 2011

Tsagouri, I., and A. Belehaki, An upgrade of the solar wind driven empirical model for the middle latitude ionospheric storm time response, J. Atmos. Sol. Terr. Phys., 70 (16), 2061-2076, DOI: $10.1016 /$ j.jastp.2008.09.010, 2008

Tsagouri, I., B. Zolesi, A. Belehaki, and L. Cander, Evaluation of the performance of the real-time updated Simplified Ionospheric Regional Model for the European area, J. Atmos. Sol. Terr. Phys., 67, 1137-1146, 2005

Tsagouri, I., K. Koutroumbas, and A. Belehaki, Ionospheric foF2 forecast over Europe based on an autoregressive modeling technique driven by solar wind parameters, Radio Sci., 44, RS0A35, DOI: 10.1029/2008RS004112, 2009.

Tsagouri, I., B. Zolesi, Lj.R. Cander, and A. Belehaki, DIAS effective sunspot number as an indicator of the ionospheric activity level over Europe, Acta Geophys., 58 (3), 491-512, 2010
Ünal, I., E.T. Şenalp, A. Yeşil, E. Tulunay, and Y. Tulunay, Performance of IRI based Ionospheric Critical Frequency Computations with reference to Forecasting, Radio Sci., 46, RS1004, DOI: 10.1029/2010RS004428, 2011.

Vainio, R., L. Desorgher, D. Heynderickx, M. Storini, E. Flückiger, R.B. Horne, G.A. Kovaltsov, K. Kudela, M. Laurenza, S. McKenna-Lawlor, H. Rothkaehl, and I.G. Usoskin, Dynamics of the Earth's particle radiation environment, Space Sci. Rev., 147, 187-231, DOI: 10.1007/s11214-009-9496-7, 2009.

Velinov, P.I.Y., and L. Mateev, Improved cosmic ray ionization model for the system ionosphere - atmosphere. Calculation of electron production rate profiles, J. Atmos. Sol. Terr. Phys., 70, 574-582, 2008a.

Velinov, P.I.Y., and L. Mateev, Analytical approach to cosmic ray ionization by nuclei with charge $\mathrm{Z}$ in the middle atmosphere distribution of galactic CR effects, Adv. Space Res., 42, 15861592, 2008b.

Velinov, P.I.Y., and P. Tonev, Electric currents from thunderstorms to the ionosphere during a solar cycle: quasi-static modeling of the coupling mechanism, Adv. Space Res., 42, 1569-1575, 2008.

Velinov, P.I.Y., A. Mishev, and L. Mateev, Model for induced ionization by galactic cosmic rays in the earth atmosphere and ionosphere, Adv. Space Res., 44, 1002-1007, 2009.

Velinov, P.I.Y., S. Asenovski, and L. Mateev, Simulation of cosmic ray ionization profiles in the middle atmosphere and lower ionosphere with account to characteristic energy intervals, C.R. Acad. Bulg. Sci., 64 (9), 1303-1310, 2011a.

Velinov, P.I.Y., A. Mishev, S. Asenovski, and L. Mateev, New operational models for cosmic ray ionization in space physics, Bulg. J. Phys., 38, 264-273, 2011 b.

Velinov, P.I.Y., S. Asenovski, and L. Mateev, Improved cosmic ray ionization model for the ionosphere and atmosphere (CORIMIA) with account of 6 characteristic intervals, C.R. Acad. Bulg. Sci., 65, 6, 2012a.

Velinov, P.I.Y., S. Asenovski, and L. Mateev, Ionization of anomalous cosmic rays in ionosphere and middle atmosphere simulated by CORIMIA code, C.R. Acad. Bulg. Sci., 65, 7, 2012 b.

Velinov, P.I.Y., S. Asenovski, and L. Mateev, Numerical calculation of cosmic ray ionization rate profiles in the middle atmosphere and lower ionosphere with relation to characteristic energy intervals, Acta Geophys., 61 (2), 494-509, 2013.

Verbeeck, C., P. Higgins, T. Colak, T. Watson, V. Delouille, B. Mampaey, and R. Qahwaji, A multi-wavelength analysis of active regions and sunspots by comparison of automatic detection, Sol. Phys., 283 (1), 67-95, DOI: 10.1007/s11207-011-9859-6, 2013.

Viljanen, A., A. Pulkkinen, R. Pirjola, K. Pajunpää, P. Posio, and A. Koistinen, Recordings of geomagnetically induced currents and a nowcasting service of the Finnish natural gas pipeline system, Space Weather, 4, S10004, DOI: 10.1029/2006SW000234, 2006.

Viljanen, A., R. Pirjola, M. Wik, A. Ádám, E. Prácser, Ya. Sakharov, and J. Katkalov, Continental scale modelling of geomagnetically induced currents, J. Space Weather Space Clim., 2, A17, DOI: http://dx.doi.org/10.1051/swsc/2012017, 2012.

Watermann, J., R. Vainio, J. Lilensten, A. Belehaki, and M. Messerotti, The state of space weather scientific modeling - an introduction, Space Sci. Rev., 147, 111-120, DOI: $10.1007 / \mathrm{s} 11214-009-9576-8,2009 a$.

Watermann, J., P. Wintoft, B. Sanahuja, E. Saiz, S. Poedts, M. Palmroth, A. Milillo, F.-A. Metallinou, C. Jacobs, N.Y. Ganushkina, I.A. Daglis, C. Cid, Y. Cerrato, G. Balasis, A.D. Aylward, and A. Aran, Models of solarwind structures and their interaction with the Earth's space environment, Space Sci. Rev., 147, 233-270, DOI: 10.1007/s11214-009-9494-9, 2009b.

Wing, S., J.R. Johnson, J. Jen, C.-I. Meng, D.G. Sibeck, K. Bechtold, J. Freeman, K. Costello, M. Balikhin, and K. Takahashi, Kp forecast models, J. Geophys. Res., 110, A04203, DOI: 10.1029/2004JA010500, 2005.

Wintoft, P., M. Wik, H. Lundstedt, and L. Eliasson, Predictions of local ground geomagnetic field fluctuations during the 7-10 
November 2004 events studied with solar wind driven models, Ann. Geophys., 23, 3095-3101, SRef-ID: 1432-0576/ag/2005-233095, 2005.

Wrenn, G.L., Time-weighted accumulations $\operatorname{ap}(\tau)$ and $K p(\tau)$, J. Geophys. Res., 92, 10125-10129, 1987.

Wrenn, G.L., and A.S. Rodger, Geomagnetic modification of the mid-latitude ionosphere: toward a strategy for the improved forecasting of foF2, Radio Sci., 24, 99-111, 1989.

$\mathrm{Wu}$, J., and P.J. Wilkinson, Time-Weighted magnetic indices as predictors of ionospheric behaviour, J. Atm. Sol. Terr. Phys, 57 (14), 1763-1770, 1995.
Zolesi, B., Lj.R. Cander, and G. De Franceschi, Simplified ionospheric regional model for telecommunication applications, Radio Sci., 28 (4), 603-612, 1993.

Zolesi, B., A. Belehaki, I. Tsagouri, and Lj.R. Cander, Real-time updating of the Simplified Ionospheric Regional Model for operational applications, Radio Sci., 39, RS2011, DOI: 10.1029/2003RS002936, 2004.

Cite this article as: Tsagouri I, Belehaki A, Bergeot N, Cid C, Delouille V, et al.: Progress in space weather modeling in an operational environment. J. Space Weather Space Clim., 2013, 3, A17. 